Article

\title{
Measure of customer satisfaction in the residential electricity distribution service using structural equation modeling
}

\author{
(D)Agenor S. Santos Neto ${ }^{1,2, *}$, (DMarcio R. C. Reis ${ }^{1,2}$, (D)A. Paulo Coimbra ${ }^{3}$, DJulio C. V. Soares ${ }^{4}$ and \\ (D)Wesley P. Calixto ${ }^{1,2, *}$ \\ ${ }^{1}$ Studies and Researches in Science and Technology Group (GCITE)/Federal Institute of Goias, \\ Brazil/Goiania. \\ ${ }^{2}$ Electrical, Mechanical \& Computer Engineering School, Federal University of Goias, Brazil/Goiania. \\ ${ }^{3}$ Institute of Systems and Robotics (ISR), University of Coimbra, Portugal/Coimbra. \\ ${ }^{4}$ Faculty of Science and Technology, Federal University of Goias, Brazil/Goiania. \\ * Correspondence:agenorsousa@ufg.br and wpcalixto@pq.cnpq.br
}

check for

updates

Citation: . Preprints, , .

Received:

Accepted:

Published:

Publisher's Note: MDPI stays neutral with regard to jurisdictional claims in published maps and institutional affiliations.

\begin{abstract}
The main objective of this study is to apply structural equation modeling with partial least squares and based on covariance to assess the satisfaction of residential electricity consumers. The methodology used compares the results of both structural equation models to indicate the model that best fits the problem of measuring the satisfaction of residential consumers of electricity concessionaires and licensees. The sample used in the survey contained questionnaire responses from 86.175 individuals considering the period from 2014 to 2018 . The constructs evaluated were satisfaction, quality, value, loyalty, and trust. Confidence interval analysis shows that all weights are significant, demonstrating the importance of all the indicators that represent the constructs. The trust, quality, and value constructs can explain $74.4 \%$ of the variability of the satisfaction construct, so the explanatory capacity of this relationship is considered substantial. Finally, the evaluation of the performance of the service provided by the electric energy concessionaires/licensees, measured by customer satisfaction, allows for the continuous improvement of services and meeting, even if minimally, the expectations of its consumers.
\end{abstract}

Keywords: Residential electricity distribution, PLS-SEM, CB-SEM, quality of service, customer satisfaction.)

\section{Introduction}

In several countries, the sectors of essential services such as electricity, water, and sewage, among others, are concerned about the well-being of citizens and the proper provision of services. For survival and profitability in a competitive scenario, service providers must develop tools capable of measuring and supporting the quality management of their services, perceived quality, and behavioral intentions of their customers. In recent decades, studies on customer satisfaction have absorbed some of the efforts of marketing researchers, research institutes, government agencies, and companies that intend to implement total quality management programs. Thus, one of the main objectives of these organizations is to search for customer satisfaction [1]. Owing to the recognition of this management principle, monitoring customer satisfaction is becoming increasingly important to assess the overall performance of companies, including electric utilities [2].

In electricity distribution services, customer satisfaction tends to be measured by technical performance, for example, by the availability of electricity. Dusky [73] points out that most of these companies are focused on providing electricity and not meeting customer expectations. However, quality of service is the important element in electricity distribution services, and its consumers are highly sensitive to different aspects of the quality of this service.

Today, customers are more informed and judicious about product supply in the market. Therefore, the evaluation of customer needs and satisfaction can improve service effectively and, consequently, lead to increased approval [3]. Filardi et al. [4] reported that the 
interruption of electricity distribution, lack of quality service, and delay in real bleshooting distribution networks have become increasingly frequent in some countries. These problems were the main factors that resulted in customer dissatisfaction, especially for residential customers.

There are many methods to measure customer satisfaction in the literature, and structural equation modeling (SEM) is one of the most commonly used methods. Using SEMs, Zeithaml, Berry and Parasuraman [5] demonstrated that behavioral intentions resulting from the impact of the quality of the services provided could be detected, especially in the company's profit. The authors evaluate 3.069 customers in the retail car sales chain, life insurers, and computers manufacturers, respectively. They presented a conceptual model of the impact of service quality to examine the reasons that lead customers to stay or abandon companies. The results highlight the customer's behavioral intent, presenting evidence of being influenced by the quality of the service provided.

Mohajerani [51] investigated the determinants and consequences of customer satisfaction the hotel industry in Iran. From the application of confirmatory factor analysis (CFA) and SEM, the author demonstrates that the construct perceived value has a significant impact on customer satisfaction in the hotel industry. In addition, there is a strong positive correlation between the constructs image $\times$ perceived quality, image $\times$ perceived value, and between perceived quality $\times$ perceived value. The results showed that an increase in customer satisfaction leads to increased loyalty.

Chakraborty and Sengupta [52] reported that India is the second-largest market for mobile phone network providers in the world. There is intense rivalry between competitors in this market, and customer satisfaction becomes a critical problem. The authors developed a model of customer satisfaction with mobile phone network providers in Kolkata/India. The results indicate that generic requirements such as the aggregation of final quality, perceived value, flexibility, and price are determinants of customer satisfaction.

Farooq et al. [53] assessed the quality of service provided by Malaysia airlines and its impact on overall customer satisfaction. This study used a convenience sampling method through a self-administered questionnaire to collect data from the interviewees. This questionnaire was created from the five dimensions of the scale for measuring airlines service quality (AIRQUAL). In addition, SEM with partial least squares (PLS-SEM) was used to test the proposed structural model. The study demonstrated that the five dimensions of the AIRQUAL scale: i) airplane tangibility, ii) terminal tangibility, iii) personnel services, iv) empathy, and v) image, contributed to customer satisfaction of Malaysia airlines.

Duarte et al. [54] found that dimensions affected online purchase intent. The authors explored the conceptual model to measure customers' perceptions to overcome the shortcomings of previous studies that did not examine the consequences of the shopping experience in online convenience stores. The empirical research uses CFA and covariance-based SEM (CB-SEM) to validate the model and test the relationships, and the results show that constructs ownership, transaction, and evaluation are the dimensions that most influence purchases in online convenience stores. The authors argue that frequent monitoring of the perceptions and expectations of these customers is a prerequisite for achieving continuous improvement in the provision of online shopping services.

Some studies emphasize reliability indicators to assess customer satisfaction with energy distribution services. Sullivan [74] proposes to measure customer satisfaction using indicators such as number of electricity service interruptions or power quality problems, total time of shutdown of electricity supply and notification of the outage in question. Similarly, Fumagalli, Garrone and Grilli [75] propose performance measures to analyze the continuity of power supply, punctuality in the processing of customer requests, reliability of the power supply, voltage values and average duration of system interruptions as a measure of satisfaction.

Bearden et al. [76] propose a broader perspective, suggesting the use of measures such as frequency of complaints, resolution of complaints and channels available for resolving complaints. On the other hand, in addition to reliability metrics, Jannadi et al. [77] adopt 
performance indicators such as courtesy, individual attention, quick care, empathy, assurance and responsiveness to measure satisfaction.

Several studies measure customer satisfaction in various segments of essential services, but there are only a few concerning electric utilities. This type of industry must develop tools capable of measuring and supporting the quality management of the services provided, perceived quality, and behavioral customer intention to ensure survival and profitability in a competitive scenario. The proposal of this work induces concessionaires/licensees of electricity to maintain data on the evolution of their indicators of the quality of service, achieving strategies that improve and lead to consumer satisfaction. In addition, in possession of the stored results obtained through this proposal, it is possible to establish an association model for concessionaires/licensees from the view of electricity consumers to facilitate the diagnosis of problems and their possible solutions. Therefore, studies that consider the potentialities arising from structural equation modeling, both with partial least squares (PLS-SEM) and covariance-based (CB-SEM), together with the monitoring of service quality indicators and forecasting in diagnoses, reduce the gap and justify the proposal of this work.

This paper presents the originality of the model of evaluation of customer satisfaction applied to the electricity sector using PLS-SEM and CB-SEM, and compares the results and evaluation which is the best model. The PLS-SEM and CB-SEM approaches analyze the cause-and-effect relationships between latent constructs [81], however, they are different in terms of results, basic assumptions and estimation procedures [82,83]. The PLS-SEM explains the variance of latent constructs by minimizing the terms of error and maximizing the $R^{2}$ values of endogenous constructs [82,84] while the CB-SEM, on the other hand, follows the procedure of estimation by maximum likelihood and aims to minimize the difference between the observed and estimated covariance matrix, without focusing on the explained variance [81].

As an innovation, the models of structural equations using multi-group comparisons seek potential changes in the measurement or relationships of constructs, which allows us to evaluate whether the theoretical model is stable. When considering its relevance, the replication of the proposed methodology is relevant to other sectors to compare their performance with international benchmarks.

The work developed requires data from the customer satisfaction questionnaires, generally available for completion on the companies' websites, making the research work not computationally costly. It can be applied in the monitoring and analysis of customer satisfaction, observing the evolution of the quality of the service provided, and assisting the development of instruments to support decision-making with concessionaires and electricity licensees. The main objective of this work is to apply structural equation modeling using partial least squares (PLS-SEM) and structural equation modeling based on covariance (CB-SEM) to evaluate the satisfaction of residential electricity customers concerning electric utilities and licensees that provide their services. The secondary objectives of this study are exploratory and descriptive analyses of customer satisfaction index data.

This manuscript has this structure: Section 2 describes some international legislation on the quality of electricity, general concepts about customer satisfaction, brief information on structural equation modeling by partial least squares (PLS-SEM), and structural equation modeling based on covariance (CB-SEM). Section 3 presents the proposed methodology. Section 4 presents the results obtained from the proposed methodology, and soon after the results are discussed. The conclusions are presented in Section 5.

\section{Teoretical background}

We presented a perspective on how electric utilities provide their services in several countries and some aspects of the quality of electricity distribution. The differences between previous expectations and perception of a given product after consumption, factors that lead to customer satisfaction, and the historical perspective of the implementation of American and European satisfaction index models are also presented here. Finally, we presented 
structural equation modeling using partial least squares (PLS-SEM) and structural equation modeling based on covariance (CB-SEM).

\subsection{Legislations of the quality of electricity}

Electric utilities strive to meet customer demands in the most economical way possible, providing service that produces reliability. To meet customer demands, power utilities need constant updating of the distribution system, operated and maintained accordingly. About $90 \%$ of all customer reliability issues are due to problems in the distribution system, so improving distribution reliability is critical to improving customer reliability [78].

The quality of electricity supplied is provided in international standards and in their local derivatives. There are no definite ways to measure residential customer satisfaction of electricity, different terminologies are used to refer to the quality of electricity in different countries. The two most common energy quality standards currently in use are IEC 610004-30 [79] and EN 50160 [80]. IEC 61000-4-30 is the standard that defines methods for monitoring energy quality, in its third edition includes current measurements, unlike previous editions that referred only to voltage measurement. EN 50160 is the European standard for energy quality, setting acceptable distortion limits for the different parameters that define alternating voltage.

The electricity sector functions as an integrated, vertical monopoly. Typically, customers are required to purchase the product electricity from only the concessionaire or licensees available in their region. Economic regulation controls these monopolies, allowing the establishment of production and sales prices. The traditional function of regulation is to protect customers from monopoly power [59].

In general, there is no international standard for regulatory agencies to measure the quality of the service provided by a concessionaire or electricity permissionary. In the United States and European countries, each region adopts its criteria, which include: i) reliability with system average interruption duration index (SAIDI), system average interruption frequency index (SAIFI), customer average interruption duration index (CAIDI), and customer average frequency index (CAIFI), ii) work accidents, iii) reaction to cable damage, iv) worst circuits in terms of interruptions (duration and frequency), v) attendance to calls (average response time), vi) complaints to the regulatory agency, vii) percentage of meters read monthly by the company, viii) service times for new customer units, and ix) customer satisfaction [55].

In terms of internationally used indexes, SAIDI and SAIFI are the most common. There are two main groups of indices used in the United States and Europe: minutes lost per year including SAIDI, customer minutes lost (CML), average system interruption duration index (ASIDI), transformer system average interruption duration index (T-SAIDI), equivalent interruption time related to the installed capacity (TIEPI), and the number of interruptions per year that, in addition to SAIFI, include customer interruptions (CI), average system frequency interruption index (ASIFI), transformer average system interruption frequency index (T-SAIFI), and equivalent number of interruptions related to the installed capacity (NIEPI) [56].

In Brazil, the particularities inherent to the quality of customer support are described in the ANEEL Normative Resolution 414/2010 [71]. This disciplinary resolution establishes the general conditions of electricity supply in an updated and consolidated manner, highlighting the quality of commercial assistance, telephone services, and information processing. The quality of the electricity supply service to the Brazilian customer is evaluated according to the interruptions, using individual continuity indicators and collective continuity indicators [72].

\subsection{Customer satisfaction}

Parasuraman, Zeithaml and Berry [13] developed a study involving twelve focus groups, three in each of the four different services investigated, being: i) bank, ii) credit cards, iii) brokerage and iv) repair and maintenance services. Based on common perceptions among the groups, the authors formally defined the quality of the service as the degree 
and type of discrepancy between the perceptions and expectations of the users, suggesting that all of them, in general, employed similar aspects of the service by which quality could be evaluated. The results obtained from these focus groups confirmed that the users were influenced by the dimensions of the process and not only by the results of the evaluation of the quality of the service.

After refinement in the research, Parasuraman, Zeithaml and Berry [13] proposed that customers evaluate the quality of services from five dimensions: i) textbftangibility that concerns the physical facilities, equipment, personnel and materials that can be perceived by the five human senses, ii) textbfreliability which translates the supplier's ability to perform the service safely and efficiently, iii) textbfpresteza which refers to the provider's availability to voluntarily serve users, providing attentive service, with accuracy and speed in response, iv) textbfsecurity which is identified as courtesy, knowledge of employees and their ability to transmit trust and v) textbfempathy that is related to how the organization cares about the user and assists him individually, the ability to show interest and personal attention.

Studies to measure customer satisfaction begin with total quality management and have expanded from the psychosocial perspective generated by marketing specialists [11]. On the other hand, projects in the production area focus on the quality management system (QMS) from the most pragmatic form of satisfaction, with marketing professionals dedicated to exploring the psychology of customer satisfaction from its formation to its impacts on future purchase behaviors [12]. Parasuraman, Zeithaml and Berry [13] describe service satisfaction as follows:

$$
S=P_{s}-E_{s}
$$

where $S$ is satisfaction, $P_{s}$ is the perception of service and $E_{s}$ is the expectation in the service. Thus, $S$ is considered the response of the evaluation of the differences between uncertain expectations and perceptions after the consumption of a given product [14]. In the analysis of Veljkovic et al. [15], customer satisfaction is linked to emotional response and the feeling of satisfaction occurs by comparing the expectations developed before purchase and the perceived performance of the product or service after the purchase. For the feeling of satisfaction to appear, probable customer expectations must be met.

Customer expectations refer to service and delivery, referring to a reference point or standard for the execution of the service, reflecting directly on their perception [15]. In this way, knowledge about customer expectations is central to the development and provision of services in all organizations [16]. Oliver [14] adds that satisfaction is essential to the well-being of customers, contributing to the process of economic stabilization and the political structures of a given nation. Customers are increasingly demanding about the market and expect more attention to meet their needs. Although these guidelines have started as marketing practices, several sectors admit that customers are elementary to their activities, making a considerable investment in training employees for adequate customer service [1].

The first nationwide customer satisfaction index is the customer satisfaction barometer (CSB), followed by the American Customer Satisfaction Index (ACSI), which contains specific information about 40 branches of activity from seven North American groups. New Zealand began working with customer satisfaction indexes, and the European Union presently recommended this index in its member countries [19]. Subsequently, Taiwan, Korea, and Brazil conducted the pilot tests [20].

The pilot European Customer Satisfaction Index (ECSI) project, born after the acceptance of the ACSI model, has the purpose of developing an instrument for measuring European market satisfaction more accurately. The ECSI model shares most of its relationship structure between latent variables (such as the ACSI model), so much so that the hypotheses are the same. The difference between the models lies in the relationships resulting from the image variable in the ECSI model, which theoretically has repercussions on expectations, satisfaction, and loyalty [22]. 
Similar to the ACSI model, the ECSI model addresses two main components: i) a structural model, formed by the set of equations that define the relationship between latent variables and, ii) measurement model, formed by the set of equations that define the relationship between latent variables and measure variables (indicators). The only difference between the models is the inclusion of the image in the ECSI model as an antecedent construct of satisfaction [23].

In Brazil, the ANEEL Customer Satisfaction Index (IASC) compares the performance of Brazilian electricity utilities from customer evaluations. The IASC calculation model is based on a qualitative consultation conducted in 2000 and is discussed with ANEEL representatives, national agencies, and electricity distributors. The IASC is composed of five variables: i) perceived quality, ii) perceived value, iii) satisfaction, iv) trust in the supplier and v) loyalty.

\subsection{Structural equation modeling}

Structural equation modeling (SEM) is a technique that analyzes the relationships of dependence, independence, and interdependence between variables through a series of simultaneous multiple regressions [24]. Although causality is somewhat complex, SEM equations aim to analyze its effects. The fundamental purpose of the SEM is to study the influence of $X$ in $Y$ and latent, the impact of $Y$ in $Z$ [25], allowing the study of the relationships between variables in sets of equations, presenting these relationships in the path diagram. In the path diagram, it is possible to check almost all the associations (measured by the model) using a set of geometric shapes and arrows.

As a confirmatory technique, SEM requires a theoretical basis for model creation, structural, and measurement models. The structural model presents the relationship between latent variables, while the measurement model presents the relationships between the observed variables and the latent variables [26]. The specification of the measurement model is a set of expressions, given by [26]:

$$
\begin{aligned}
& x_{1}=F_{1}+e_{1} \\
& x_{2}=F_{1}+e_{2} \\
& x_{3}=F_{2}+e_{3} \\
& x_{4}=F_{2}+e_{4}
\end{aligned}
$$

where $F_{1}$ and $F_{2}$ are the latent variables, and $e_{1}, e_{2}, e_{3}$ and $e_{4}$ are the measurement errors of variables $x_{1}, x_{2}, x_{3}$, and $x_{4}$, respectively. The purpose of the structural model is similar to that of the measurement model; however, it specifies the dependency relationships between the latent variables of the model and the response. This model is represented by:

$$
\begin{aligned}
& F_{1}=y_{1}+r_{1} \\
& F_{2}=y_{1}+r_{2}
\end{aligned}
$$

where $r_{1}$ and $r_{2}$ are the residuals representing the model prediction error. The modeling of structural equations is a technique of second-generation multivariate statistical techniques for data analysis, enabling answers to interrelate, systematic, and comprehensive questions. This purpose is achieved by simultaneously modeling relationships between multiple dependent and independent constructs [27], [28].

Among the structural equation modeling (SEM) methodologies, there are two in the literature that stand out: i) structural equation modeling by partial least squares (PLSSEM) and ii) structural equation modeling based on covariance (CB-SEM). The PLS-SEM approach is causal modeling that aims to maximize the explained variance of dependent latent constructs, contrary to the objective of the CB-SEM approach of reproducing the theoretical covariance matrix without focusing on the explained variance [40]. However, 
both approaches are complementary in the way that the advantages of the nonparametric and variance-based PLS-SEM approach are the disadvantages of the Parametric CB-SEM approach and vice versa $[40,85,86]$.

\subsubsection{Partial Least Squares Structural Equation Modeling}

Partial least squares structural equation modeling (PLS-SEM) is applied in the calibration, monitoring, and control of industrial processes, in which processes can have hundreds of controllable variables and dozens of outputs [29]. The PLS-SEM regression method refers to the estimation technique of the linear regression model, based on the decomposition of the matrices of the response variables and predictor variables. In this case, the algorithm employed analyzes both arrays and extracts the components, which are directly important to both sets of variables [30].

Morelatto [31] described that the PLS-SEM regression method presents the advantages of i) modeling regressions with multiple response variables, ii) accepting multicollinearity, and iii) predicting the factors produced due to high covariances with the response variables. In contrast, the disadvantages of the method are: i) difficulty in interpreting loads of factors, ii) the significance tests of the estimators of the regression coefficients are performed according to research methods because their distributions are not known, and iii) the absence of test statistics for the model.

PLS-SEM is essentially a prediction technique and not an interpretation technique. However, some studies have investigated the factors extracted via PLS-SEM [31]. SEM has been used in several areas because of the need to overcome certain limitations of first-generation multivariate techniques. Although the PLS-SEM approach is usually used in conducting research conducted on data and information based on the characteristics and opinions of groups of individuals, this method is the most appropriate for modeling complex relationships with multiple relationships of dependence and independence between latent variables [32], and is useful for applications in experiments and file data [33].

\subsubsection{Covariance-based structural equation modeling}

Covariance-based structural equation modeling (CB-SEM) verifies the minimization of differences between the observed and expected covariance matrices. This model emphasizes confirmatory factor analysis in a more applied way [48]. CB-SEM has been used as a method for the evaluation and development of theory in applied social sciences, mainly in the marketing field [24]. The process of application of CB-SEM allows the evaluation of measurement models and structural pathways, especially when the structural model involves multiple dependent variables [60].

The CB-SEM is associated with the structuring process using maximum likelihood, which focuses on estimating a set of parameters of the model so that the matrix of theoretical covariance, implicit in the system of structural equations, is as close as possible to the observed empirical covariance matrix [62]. In CB-SEM, endogenous variables are not understood as perfect and fully explained by the variables of the model, which exert influence on them and are still defined from the error [63]. Therefore, measurement models should be evaluated for their reliability of internal consistency and validity. Specific measures, necessarily include composite reliability as a means of evaluating the reliability of internal consistency, convergent validity, and discriminant validity [48].

\section{Methodology}

This section presents the methodology used to understand how different indicators contribute to achieving residential electricity consumer satisfaction, assessing the satisfaction of these consumers about concessionaires and licensees that provide electricity distribution services. Therefore, verification is carried out on the instrument and the procedures used for data collection, presenting the process of descriptive data analysis and the construction of structural equation modeling based on partial least squares and structural equation 
modeling based on covariance. The proposed process is illustrated in Figure 1, with a brief description of the five stages required for the resulting model.

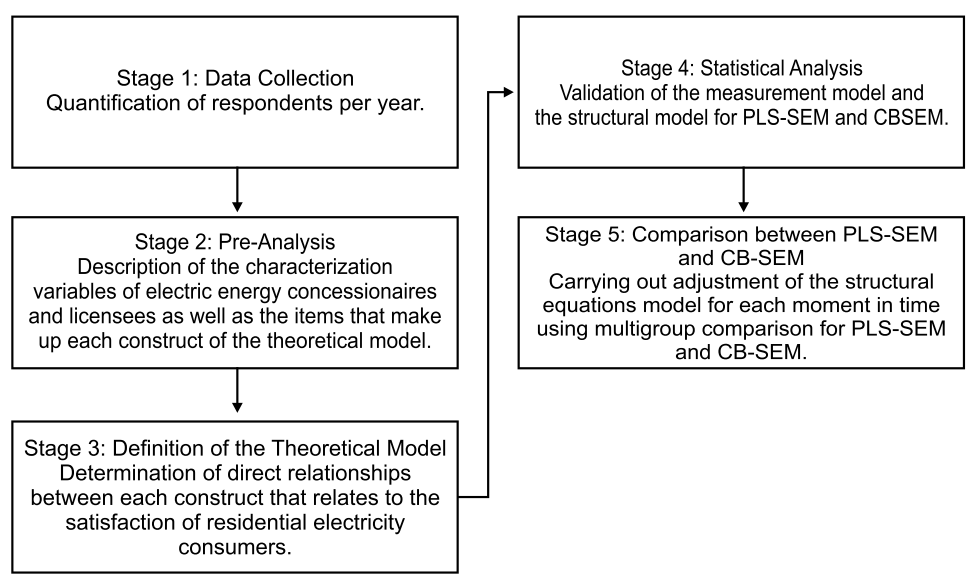

Figure 1. Flowchart of the process of modeling structural equations

\subsection{Data Collection}

From the electronic system of the citizen information service (SESIC), it is possible to obtain access to the information necessary to calculate the satisfaction of residential electricity consumers. In this way, reference data are obtained regarding the customer's perception of the regulation, production, transmission, distribution, and commercialization of electric energy.

The data obtained by SESIC are generally formatted in a structure for mathematical processing, consisting of recording observations and variables of interest. SESICs were used in most cases .CSV files. The defining variables used were: household, sex, age group, education, family income, and value of the last energy bill, among others.

\subsection{Pre-analysis}

With the data in hand, pre-treatment was carried out based on the population to be studied. Thus, the population is made up of residential electricity consumers and the number of respondents varies according to the size of each energy distributor. In the description of the qualitative variables characterizing the energy companies and the sample, absolute and relative frequencies are used, while in the description of quantitative variables and the description constructs' items, measures of position, central tendency and dispersion are used.

The grouping analysis of individuals was performed using the non-hierarchical $k$ prototypes method. The k-prototype grouping combines the $k$-means and k-modes methods, allowing the simultaneous use of numerical and categorical variables in the grouping. In the pre-treatment, after identifying the outliers, it is necessary to verify whether the exclusion of data produces or does not underestimate the results of the analysis.

\subsection{Theoretical Model}

In the proposal of the model for assessing the satisfaction of residential electricity customers, the approach of structural equations in which the main measurement characteristics of the American Customer Satisfaction Index (ACSI) and the ANEEL Customer Satisfaction Index (IASC) are considered. To build a structural equation model that represents the factors that lead to the satisfaction of residential electricity consumers, it is necessary to first elaborate the theoretical model that determines the multiple dependency relationships between the variables. In this way, the satisfaction, quality, value, loyalty and trust constructs were tested. 
In this proposal, satisfaction is considered as the assessment of the degree of adjustment of the service provided by concessionaires/licensees of electric energy to the expectations of the customer. Quality is the customer's perception of fitness guided by their needs, expectations and how much the customer perceives the quality in the service provided. Value is considered as the assessment of the relationship between costs and benefits perceived by the consumer in relation to electricity services. Loyalty is defined as the consumer's commitment to continue consuming the service consistently depending on the tariff, supply or service, even though they know that they cannot change providers since most of the time there is monopolisation of the power distribution service. Trust assesses whether consumers consider electricity suppliers to be reliable, concerned about consumers themselves, competent in providing the right services and information providers.

Figure 2 illustrates the direct relationships between each construct. Thus, trust is related to perceived quality, satisfaction and loyalty. Perceived quality is related to value and satisfaction, and value is related only to satisfaction. Finally, satisfaction is related to loyalty.

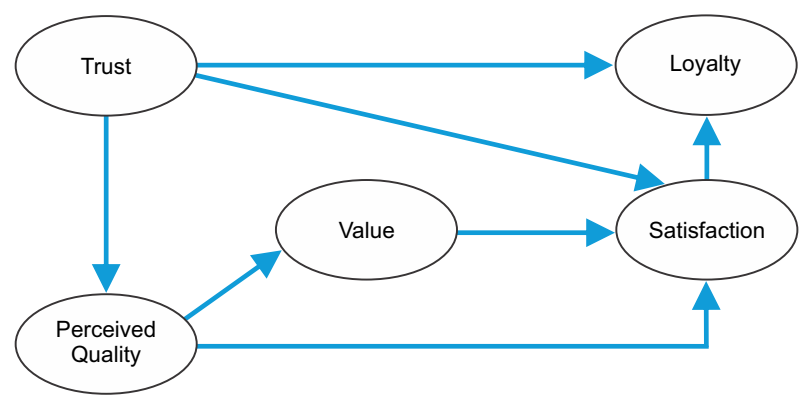

Figure 2. Flowchart for the evaluation of satisfaction of residential electricity consumer.

The theoretical model illustrated in Figure 2 consists of a systematic set of relationships that provide explanations about consumer satisfaction and is not restricted to the theory of consumer satisfaction, but is grounded in experience and practice obtained from observation.

\subsection{Statistical Analysis}

To verify the validity of the ability of each construct's set of indicators to accurately represent its respective concept, a measurement model was developed in which dimensionality, reliability, convergent validity, and discriminant validity were evaluated. To verify the dimensionality of the constructs, the Kaiser criterion was used in this study. Convergent and discriminant validity were used as the criterion proposed by Fornell [39], which indicates convergent validity, if the average variance extracted (AVE) is greater than $50 \%$ or $40 \%$ in the case of exploratory research, while discriminant validity occurs when the AVE of the construct is greater than the shared variance of this construct with others.

To measure reliability, Cronbach's alpha (CA) and composite reliability (CR) were used. The CA and CR indicators must be greater than 0.70 to indicate the reliability of the construct, and in exploratory research values above 0.60 are also accepted. To verify the discriminant validity, the cross-factor loading method is used, which indicates discriminant validity when the factor loading of the item is greater than all of its cross-factor loadings.

For the PLS-SEM approach, the bootstrap method was used to calculate the confidence intervals for the weights of the measurement model and the coefficients of the structural model, providing information on the variability of the estimated parameters, thus promoting the validation of the results. In the CB-SEM approach, the model quality parameters were used: comparative fit index (CFI), Tucker-Lewis index (TLI), and root mean square error of approximation (RMSEA), in addition to the $p$-value to verify that the RMSEA is statistically greater than 0.05. For the desired adjustment, CFI and TLI were expected to be greater than 0.80 . The CFI and TLI values vary in the interval $[0,1]$, and the closer the value is to 1 , the better the model fit. The RMSEA must present an index of less than 0.10 , the ideal being below 0.05 . 
3.5. Method to compare structural equation modeling based on partial least squares and covariance-based SEM

One of the objectives of this work is to compare the results obtained by structural equation modeling: i) based on partial least squares (PLS-SEM) and ii) based on covariance (CB-SEM). To compare the two different techniques, the structural equation model and the measurement model were adjusted for each period/time of the analysis, and the models were compared by multigroup.

Multigroup analysis is performed on time series, looking for potential changes in the measure or the relationships of the constructs, allowing the assessment of whether the theoretical model is stable over time or not. For the formal tests to compare the weights and structural coefficients between times, the Student's $t$-test was used with a grouped standard deviation of the weights or coefficients within the tested models.

\section{Results}

In this section, the results obtained by applying the proposed methodology are presented. The data used come from concessionaires and licensees of the Brazilian Electricity Regulatory Agency (ANEEL/Brazil). The population for the construction of the database is formed by the set of residential electricity consumers interviewed for the composition of the ANEEL Consumer Satisfaction Index (IASC), in the period from 2014 to 2018. The IASC is obtained annually from a sample survey conducted with residential consumers of all distributors, concessionaires and licensees, who operate in the Brazilian territory. Approximately 27.000 interviews are conducted per year.

\subsection{Database Construction}

Concessionaires/licensees concentrate their services in urban areas, however, according to current regulations, electricity distribution services are composed of urban and rural consumers. As the number of rural consumers $\approx 5 \%$ is lower than that of urban consumers $\approx 85 \%$, the needs of rural areas end up being ignored. The annual satisfaction survey conducted by ANEEL uses samples only from urban residential consumers. Even other consumers in other categories, such as trade, industry and government, are not analyzed. Therefore, the IASC evaluates distributors only based on the opinion of urban residents. Table 1 provides the distribution of consumer units $(\mathrm{CU})$ in the various consumption classes for all Brazilian concessionaires/licensees.

Table 1. Consumer units by consumption class.

\begin{tabular}{lcc}
\hline \multicolumn{1}{c}{ Consumption class } & No. CU & \% \\
\hline Commercial and Services & 1.141 .705 .208 & 7,24 \\
\hline Own Consumption & 1.968 .873 & 0,01 \\
\hline Streetlight & 17.611 .665 & 0,11 \\
\hline Industrial & 118.022 .560 & 0,75 \\
\hline Government & 115.039 .889 & 0,73 \\
\hline Residential & 13.471 .190 .674 & 85,45 \\
\hline Rural & 854.493 .946 & 5,42 \\
\hline Rural Farmer & 6.713 .438 & 0,04 \\
\hline Rural Irrigating & 22.061 .727 & 0,14 \\
\hline Civil Service & 16.708 .356 & 0,11 \\
\hline \multicolumn{1}{c}{ TOTAL } & $\mathbf{1 5 . 7 6 5 . 5 1 6 . 3 3 6}$ & \\
\hline \hline
\end{tabular}

The research conducted in this work analyzes the satisfaction of the $\approx 85 \%$ of the customers of the concessionaires/licensees that are mostly urban residential. The satisfaction of other clients is not measured, as they are not considered in the sampling of the annual satisfaction survey conducted by ANEEL. Data for assessing the satisfaction of residential electricity consumers were requested from the ANEEL via the electronic system of the citizen information service (SESIC). For 2014 and 2015, a total of 25.186 interviews were 
conducted each year, 20.230 of which were interviews in 63 concessionaires and 4.956 interviews in 38 licensees. In 2016 and 2017, 24.926 interviews were conducted each year, with 19.970 interviews held in 63 concessionaires and 4.956 interviews in 38 licensees. In 2018, 23.446 interviews were conducted, 18.490 of which were in the 54 concessionaires and 4.956 interviews in the 38 licensees.

After the construction of the database, a pre-analysis was carried out, treating the data to remove those interviewed who did not answer all the questions. With the processed data, there were: 16.704 individuals in 2014, 19.763 individuals in 2015, 19.782 individuals in 2016, 14.618 individuals in 2017 and 15.308 individuals in 2018, totaling 86.175 individuals. The questionnaire contained 50 questions, of which 32 questions were related to the constructs satisfaction, quality, value, loyalty and trust, while the other questions strive to promote the descriptive analysis of the variables that characterize the sample.

\subsection{Descriptive Analysis of Variables}

With the database treated, it is possible to perform a descriptive analysis of the variables characterizing the individuals, as shown in Table 2, in which $79.20 \%$ of respondents are responsible for the household.

Most individuals were female $(61.71 \%), 21.50 \%$ were between 46 and 55 years old, and $20.80 \%$ were between 36 and 45 years old, and these were the most frequent age groups. All individuals lived in the interview's home, lived in the city for more than six months, knew the name of the electricity company, did not work and had no relatives who worked at the electricity company, and all knew the value of the electricity bill.

In most respondents, energy use is exclusively residential, and they do not provide energy to third parties (99.98\%). As for the level of education, $35.40 \%$ of respondents had not completed elementary school, and $29.30 \%$ had completed high school. As for family income, $45.70 \%$ of individuals receive from US $\$ 3.974,00$ to US $\$ 9.937,00$ and $31.3 \%$ receive annually from US\$ $1.807,00$ to US\$ $3.974,00$. Thus, $77 \%$ of individuals have an annual income between US\$1.807,00 and US\$ 9.937,00.

Table 3 shows the groups $\times$ variables used in the grouping process, in which the difference between groups and variable values was observed $(p$-value $<0.05)$. There were three groups: Group 1, Group 2, and Group 3. In Group 1 it was observed that: $87.10 \%$ of the individuals interviewed are responsible for the household; $74.60 \%$ are men; $28.80 \%$ are aged between 46 and 55 years; $64.30 \%$ have completed high school with an annual family income between US\$ $3.974,00$ and US\$ 9.937,00 and 55.10\% paid more than US\$28.95 in the last amount of the electricity bill.

Group 2 contained $78.10 \%$ of the interviewed individuals responsible for the household, $74.10 \%$ were women over 60 years old, $75.8 \%$ had only incomplete primary education, and $47.8 \%$ had an annual family income between US $\$ 1.807,00$ and US $\$ 3.974,00$. This group has the lowest values for the last electricity bill, with $38 \%$ of individuals paying approximately US\$12.00. Group 3 comprised $73.2 \%$ of the individuals interviewed as responsible for the household, $77.70 \%$ were women, $38.4 \%$ were aged between 26 and 35 years, $52.8 \%$ had completed high school with an annual family income between US\$ $3.974,00$ and US\$ 9.937,00 and the last amount on the energy bill between US\$19.00 and US\$28.95.

\subsection{Description of the Theoretical Model}

In the description of the theoretical model, the constructs satisfaction, quality, value, loyalty, and trust are tested. Questions from the ANEEL Consumer Satisfaction Index (IASC) are shown in Table 4 and in Figure 3 the distribution and discrepancies in the data of the observable variables that comprise each construct are presented. 
Table 2. Descriptive analysis of sample characterization variables.

\begin{tabular}{|c|c|c|c|}
\hline \multicolumn{2}{|c|}{ Variables } & $\mathbf{N}$ & $\%$ \\
\hline \multirow[t]{2}{*}{ Responsible by domicile } & Spouse of the responsible & 17912 & $20,8 \%$ \\
\hline & Yes & 68263 & $79,2 \%$ \\
\hline \multirow[t]{2}{*}{ Gender } & Male & 52634 & $61,1 \%$ \\
\hline & Female & 33541 & $38,9 \%$ \\
\hline \multirow[t]{7}{*}{ Age group } & Up to 18 years old & 299 & $0,3 \%$ \\
\hline & Between 18 and 25 years old & 5722 & $6,6 \%$ \\
\hline & Between 26 and 35 years old & 15036 & $17,5 \%$ \\
\hline & Between 36 and 45 years old & 17901 & $20,8 \%$ \\
\hline & Between 46 and 55 years old & 18547 & $21,5 \%$ \\
\hline & Between 56 and 65 years old & 15492 & $18,0 \%$ \\
\hline & Over 65 years old & 13169 & $15,3 \%$ \\
\hline \multirow[t]{2}{*}{ Lives at home } & No & 0 & $0,0 \%$ \\
\hline & Yes & 86175 & $100,00 \%$ \\
\hline \multirow{2}{*}{$\begin{array}{l}\text { Lives in the city for } \\
\text { over } 6 \text { months }\end{array}$} & No & 0 & $0,0 \%$ \\
\hline & Yes & 86175 & $100,00 \%$ \\
\hline \multirow[t]{2}{*}{ Know the name of the concessionaire } & No & 0 & $0,0 \%$ \\
\hline & Yes & 86175 & $100,00 \%$ \\
\hline \multirow{2}{*}{$\begin{array}{l}\text { Works at the electric } \\
\text { power company }\end{array}$} & No & 86175 & $100,00 \%$ \\
\hline & Yes & 0 & $0,0 \%$ \\
\hline \multirow{2}{*}{$\begin{array}{l}\text { Exclusively residential } \\
\text { consumption }\end{array}$} & No & 12 & $0,0 \%$ \\
\hline & Yes & 86163 & $100,00 \%$ \\
\hline \multirow[t]{2}{*}{ Has power meter } & No & 0 & $0,0 \%$ \\
\hline & Yes & 86175 & $100,00 \%$ \\
\hline \multirow[t]{2}{*}{ Provides energy to third parties } & No & 86174 & $100,00 \%$ \\
\hline & Yes & 1 & $0,0 \%$ \\
\hline \multirow{2}{*}{ Energy supply } & Not normal & 0 & $0,0 \%$ \\
\hline & Normal & 86175 & $100,0 \%$ \\
\hline \multirow{2}{*}{ Know the account value } & No & 0 & $0,0 \%$ \\
\hline & Yes & 86175 & $100,0 \%$ \\
\hline \multirow{6}{*}{ Education level } & Incomplete elementary & 30525 & $35,4 \%$ \\
\hline & Complete elementary & 12082 & $14,0 \%$ \\
\hline & Incomplete high school & 5969 & $6,9 \%$ \\
\hline & Complete high school & 25225 & $29,3 \%$ \\
\hline & Incomplete higher education & 3475 & $4,0 \%$ \\
\hline & Complete higher education & 8899 & $10,3 \%$ \\
\hline \multirow[t]{7}{*}{ Annual family income } & Less than US $\$ 1.992,45$ & 9303 & $10,8 \%$ \\
\hline & From US\$ $1.992,45$ to US\$ $3.984,91$ & 26991 & $31,3 \%$ \\
\hline & From US\$3.984,92 to US\$ $9.962,26$ & 40938 & $47,5 \%$ \\
\hline & From US\$ $9.962,27$ to US\$ $19.924,53$ & 7227 & $8,4 \%$ \\
\hline & From US $\$ 19.924,54$ to US $\$ 29.886,79$ & 1266 & $1,5 \%$ \\
\hline & From US $\$ 29.886,80$ to US $\$ 39.849,06$ & 288 & $0,3 \%$ \\
\hline & More than US\$ $39.849,06$ & 162 & $0,2 \%$ \\
\hline Last account value & Mean (S.D.) & 33,79 & $1.610,72$ \\
\hline
\end{tabular}

Table 3. Description of the groups as to categorical variables.

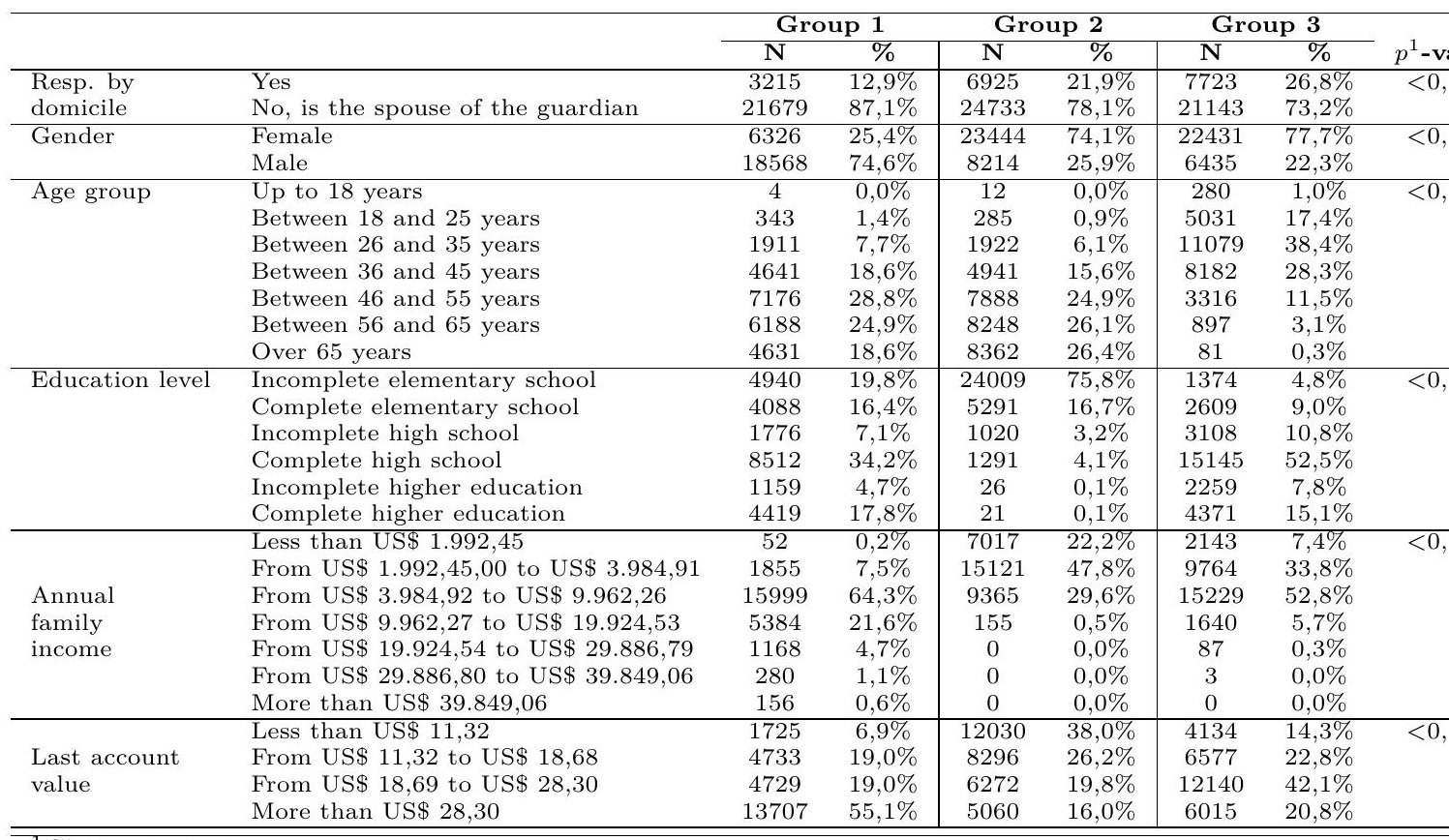


Table 4. List of items of the ANEEL Index of Consumer Satisfaction.

\begin{tabular}{|c|c|c|}
\hline Constructs & Items & Description \\
\hline \multirow{4}{*}{ Trust } & TRU1 & The concessionaire/licensee very reliable. \\
\hline & TRU2 & $\begin{array}{l}\text { I am sure the concessionaire/licensee cares about the interests of its } \\
\text { customers. }\end{array}$ \\
\hline & TRU3 & $\begin{array}{l}\text { The concessionaire/licensee very competent in providing its services to } \\
\text { customers. }\end{array}$ \\
\hline & TRU4 & The concessionaire/licensee gives true/correct information to its customers. \\
\hline Quality & QUA1 & General assessment of the quality of services. \\
\hline \multirow{4}{*}{ Value } & VAL1 & How do you evaluate the price of electricity? \\
\hline & VAL2 & $\begin{array}{l}\text { Thinking about the facilities that energy brings to your life you would say } \\
\text { the price is. }\end{array}$ \\
\hline & VAL3 & $\begin{array}{l}\text { Thinking about the quality of the electricity supply as you rate the price } \\
\text { paid. }\end{array}$ \\
\hline & VAL4 & $\begin{array}{l}\text { Thinking about the aspects related to customer service how you evaluate } \\
\text { the price paid. }\end{array}$ \\
\hline \multirow{19}{*}{ Satisfaction } & SAT1 & Overall assessment of satisfaction with services. \\
\hline & SAT2 & Power supply without interruption, i.e. without power outage. \\
\hline & SAT3 & $\begin{array}{l}\text { Power supply without variation in voltage, i.e. without alternating strong } \\
\text { light with weak light. }\end{array}$ \\
\hline & SAT4 & $\begin{array}{l}\text { Punctuality in the provision of services, that is, provide the service on the } \\
\text { promised time/deadline. }\end{array}$ \\
\hline & SAT5 & Easy to contact the company (in person, by phone, via internet etc.) \\
\hline & SAT6 & Cordiality in service, i.e. education/courtesy of the staff who attend. \\
\hline & SAT7 & $\begin{array}{l}\text { Advance warnings about power outages when there is a delay in payment } \\
\text { of the account. }\end{array}$ \\
\hline & SAT8 & $\begin{array}{l}\text { Reliability of the solutions given, that is, definitive solution of the problem } \\
\text { presented. }\end{array}$ \\
\hline & SAT9 & Explanation about proper energy use, how to use efficiently, not to waste. \\
\hline & SAT10 & $\begin{array}{l}\text { Security in the amount charged, that is, reliability in reading the } \\
\text { consumption performed by the concessionaire/licensee are always correct } \\
\text { account. }\end{array}$ \\
\hline & SAT11 & $\begin{array}{l}\text { Ease of access to the locations/means of payment of the account, i.e. places } \\
\text { for payment, direct debit etc. }\end{array}$ \\
\hline & SAT12 & Speed of power return when there is interruption/when light is lacking. \\
\hline & SAT13 & Quick responses to customer requests. \\
\hline & SAT14 & $\begin{array}{l}\text { Early warnings about power outages when there is a need for repairs/repairs } \\
\text { of the network. }\end{array}$ \\
\hline & SAT15 & Even care to all consumers, that is, there is no discrimination. \\
\hline & SAT16 & Information/guidance on the risks associated with the use of electricity. \\
\hline & SAT17 & $\begin{array}{l}\text { Clarifications about their rights and duties, such as the right to safe energy } \\
\text { and quality and the duty to pay the bill on time. }\end{array}$ \\
\hline & SAT18 & $\begin{array}{l}\text { Detailing of the accounts, i.e. adequate/detailed information on the } \\
\text { account. }\end{array}$ \\
\hline & SAT19 & Thinking about the quality of services, in general, you would say you are. \\
\hline \multirow{4}{*}{ Loyalty } & LOY1 & What are the odds of changing your electricity company? \\
\hline & LOY2 & $\begin{array}{l}\text { Suppose another company's price is better. What are the odds of changing } \\
\text { your electricity company? }\end{array}$ \\
\hline & LOY3 & $\begin{array}{l}\text { Assuming that the quality of another supplier's power supply is better } \\
\text { What are the odds of changing your electricity company? }\end{array}$ \\
\hline & LOY4 & $\begin{array}{l}\text { Assuming customer service is better in another, What are the odds of } \\
\text { changing your electricity company? }\end{array}$ \\
\hline
\end{tabular}

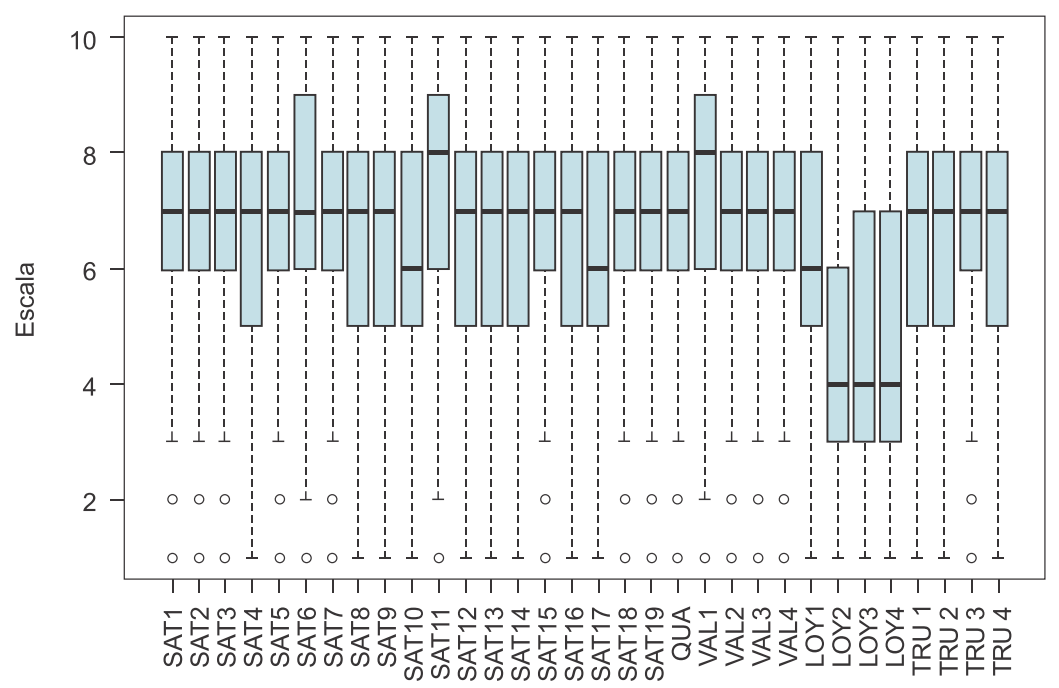

Figure 3. Constructs used and items evaluated. 
The satisfaction construct tends to be within what is expected for the items: SAT1, SAT2, SAT3, SAT4, SAT5, SAT7, SAT8, SAT9, SAT10, SAT12, SAT13, SAT14, SAT15, SAT16, and SAT17. Items SAT6, SAT11, and SAT18 tend to be better than expected and as for SAT19, there is a tendency that the quality is not ideal. Regarding the quality construct, the interviews indicated that QUA was as expected. In the value construct in items VAL2 and VAL3, there is a tendency that the amount paid is neither cheap nor expensive, and in relation to items VAL1 and VAL4, there is a tendency for the amount paid to be expensive.

Some rating scales are built from items whose conceptual meaning is opposite to that of other items. In these cases, the assigned value must be inverted to calculate the score. In this work, for the loyalty construct, an inversion is performed so that its items are in the same direction as the other constructs. Overall, the interviews indicate that LOY1 would depend on some factors, however, if there was another company with better LOY2, LOY3, and LOY4, the trend would be to switch from one utility company to another. Regarding the trust construct, items TRU1, TRU2, TRU3, and TRU4 tend to neither agree nor disagree. Table 5 summarizes the analyses of each construct.

Table 5. Descriptive analysis of the constructs used and their items.

\begin{tabular}{|c|c|c|c|c|}
\hline Construct & Item & Average & SD & CI - 95\% ${ }^{1}$ \\
\hline \multirow{4}{*}{ Trust } & TRU1 & 6,674 & 2,008 & {$[6,661 ; 6,688]$} \\
\hline & TRU2 & 6,485 & 2,110 & {$[6,471 ; 6,498]$} \\
\hline & TRU3 & 6,914 & 1,980 & {$[6,902 ; 6,929]$} \\
\hline & TRU4 & 6,704 & 2,031 & {$[6,691 ; 6,718]$} \\
\hline Quality & QUA & 7,012 & 1,989 & {$[6,999 ; 7,025]$} \\
\hline \multirow{4}{*}{ Value } & VAL1 & 7,668 & 1,897 & {$[7,656 ; 7,681]$} \\
\hline & VAL2 & 7,018 & 1,977 & {$[7,005 ; 7,031]$} \\
\hline & VAL3 & 7,019 & 1,925 & {$[7,006 ; 7,032]$} \\
\hline & VAL4 & 7,007 & 1,905 & {$[6,994 ; 7,019]$} \\
\hline \multirow{19}{*}{ Satisfaction } & SAT1 & 6,958 & 2,157 & {$[6,944 ; 6,973$} \\
\hline & SAT2 & 6,979 & 2,079 & {$[6,965 ; 6,992]$} \\
\hline & SAT3 & 6,884 & 2,084 & {$[6,870 ; 6,898]$} \\
\hline & SAT4 & 6,885 & 2,140 & {$[6,872 ; 6,900]$} \\
\hline & SAT5 & 6,921 & 2,212 & {$[6,905 ; 6,935]$} \\
\hline & SAT6 & 7,388 & 2,041 & {$[7,375 ; 7,402]$} \\
\hline & SAT7 & 6,837 & 2,231 & {$[6,823 ; 6,853]$} \\
\hline & SAT8 & 6,870 & 2,054 & {$[6,857 ; 6,884]$} \\
\hline & SAT9 & 6,594 & 2,236 & {$[6,580 ; 6,608]$} \\
\hline & SAT10 & 6,428 & 2,342 & {$[6,414 ; 6,444]$} \\
\hline & SAT11 & 7,459 & 2,052 & {$[7,445 ; 7,473]$} \\
\hline & SAT12 & 6,716 & 2,211 & {$[6,701 ; 6,731]$} \\
\hline & SAT13 & 6,697 & 2,117 & {$[6,683 ; 6,712]$} \\
\hline & SAT14 & 6,663 & 2,373 & {$[6,647 ; 6,679]$} \\
\hline & SAT15 & 7,049 & 2,045 & {$[7,035 ; 7,062]$} \\
\hline & SAT16 & 6,608 & 2,229 & {$[6,593 ; 6,623]$} \\
\hline & SAT17 & 6,476 & 2,238 & {$[6,461 ; 6,490]$} \\
\hline & SAT18 & 7,092 & 2,059 & {$[7,078 ; 7,106]$} \\
\hline & SAT19 & 6,549 & 1,988 & {$[6,535 ; 6,564]$} \\
\hline \multirow{4}{*}{ Loyalty } & LOY1 & 6,032 & 2,300 & {$[6,017 ; 6,047]$} \\
\hline & LOY2 & 4,486 & 2,596 & {$[4,469 ; 4,504]$} \\
\hline & LOY3 & 4,453 & 2,627 & {$[4,436 ; 4,473]$} \\
\hline & LOY4 & 4,603 & 2,630 & {$[4,587 ; 4,620]$} \\
\hline
\end{tabular}

${ }^{1}$ Bootstrap interval

\subsection{Measurement Model}

In the analysis of measurement models for the modeling of structural equations based on partial least squares (PLS-SEM), the convergent validity, discriminant validity, and reliability of the constructs were verified. Convergent validity guarantees that the indicators of a given construct are sufficiently correlated to measure the latent concept. Discriminant validity checks whether the constructs effectively measure different aspects of the phenomenon of interest. Reliability indicates the consistency of the measures in the concept to be measured. The results show that all items have factor loadings above 0.50; therefore, it is not necessary to exclude items. For confidence intervals (CI - 95\%) all weights are significant, indicating the importance of all items for the formation of indicators that represent the constructs. Table 6 shows the weights, factor loadings, and commonalities of the general measurement model for PLS-SEM. Tables 7 and 8 show the analysis results of 
the convergent validity, discriminant validity, dimensionality, and reliability of the constructs of the general measurement model.

Table 6. General measurement model for modeling structural equations based on partial least squares.

\begin{tabular}{|c|c|c|c|c|c|}
\hline Construct & Item & Weight & CI - 95\% ${ }^{1}$ & $\mathbf{F L}^{2}$ & Com. $^{3}$ \\
\hline \multirow{4}{*}{ Trust } & TRU1 & 0,273 & {$[0,272 ; 0,273]$} & 0,894 & 0,800 \\
\hline & TRU2 & 0,279 & {$[0,278 ; 0,280]$} & 0,911 & 0,831 \\
\hline & TRU3 & 0,280 & {$[0,279 ; 0,282]$} & 0,904 & 0,817 \\
\hline & TRU4 & 0,275 & {$[0,274 ; 0,276]$} & 0,904 & 0,817 \\
\hline Quality & QUA1 & 1,000 & {$[1,000 ; 1,000]$} & 1,000 & 1,000 \\
\hline \multirow{4}{*}{ Value } & VAL1 & 0,265 & {$[0,261 ; 0,269]$} & 0,838 & 0,703 \\
\hline & VAL2 & 0,274 & {$[0,270 ; 0,277]$} & 0,911 & 0,831 \\
\hline & VAL3 & 0,290 & {$[0,288 ; 0,293]$} & 0,925 & 0,856 \\
\hline & VAL4 & 0,284 & {$[0,280 ; 0,287]$} & 0,914 & 0,835 \\
\hline \multirow{19}{*}{ Satisfaction } & SAT1 & 0,077 & {$[0,077 ; 0,078]$} & 0,720 & 0,518 \\
\hline & SAT2 & 0,067 & {$[0,066 ; 0,067]$} & 0,755 & 0,570 \\
\hline & SAT3 & 0,065 & {$[0,064 ; 0,066]$} & 0,754 & 0,568 \\
\hline & SAT4 & 0,072 & {$[0,071 ; 0,072]$} & 0,811 & 0,658 \\
\hline & SAT5 & 0,066 & {$[0,066 ; 0,066]$} & 0,771 & 0,595 \\
\hline & SAT6 & 0,064 & {$[0,064 ; 0,065]$} & 0,765 & 0,585 \\
\hline & SAT7 & 0,062 & {$[0,062 ; 0,063]$} & 0,740 & 0,547 \\
\hline & SAT8 & 0,073 & {$[0,073 ; 0,074]$} & 0,831 & 0,690 \\
\hline & SAT9 & 0,067 & {$[0,066 ; 0,067]$} & 0,765 & 0,586 \\
\hline & SAT10 & 0,076 & {$[0,076 ; 0,077]$} & 0,771 & 0,594 \\
\hline & SAT11 & 0,053 & {$[0,052 ; 0,054]$} & 0,665 & 0,442 \\
\hline & SAT12 & 0,071 & {$[0,070 ; 0,071]$} & 0,796 & 0,633 \\
\hline & SAT13 & 0,075 & {$[0,074 ; 0,075]$} & 0,838 & 0,703 \\
\hline & SAT14 & 0,067 & {$[0,067 ; 0,068]$} & 0,758 & 0,574 \\
\hline & SAT15 & 0,069 & {$[0,069 ; 0,069]$} & 0,792 & 0,627 \\
\hline & SAT16 & 0,068 & {$[0,068 ; 0,068]$} & 0,766 & 0,587 \\
\hline & SAT17 & 0,070 & {$[0,069 ; 0,070]$} & 0,770 & 0,593 \\
\hline & SAT18 & 0,069 & {$[0,069 ; 0,070]$} & 0,762 & 0,581 \\
\hline & SAT19 & 0,076 & {$[0,076 ; 0,077]$} & 0,689 & 0,474 \\
\hline \multirow{4}{*}{ Loyalty } & LOY1 & 0,348 & {$[0,346 ; 0,351]$} & 0,804 & 0,646 \\
\hline & LOY2 & 0,260 & {$[0,258 ; 0,262]$} & 0,894 & 0,800 \\
\hline & LOY3 & 0,266 & {$[0,264 ; 0,268]$} & 0,914 & 0,836 \\
\hline & LOY4 & 0,269 & {$[0,267 ; 0,271]$} & 0,908 & 0,824 \\
\hline
\end{tabular}

Table 7. Validation of the general measurement model for the modeling of structural equations based on partial least squares.

\begin{tabular}{ccccccc}
\hline Construct & Item & $\mathbf{C A}^{1}$ & $\mathbf{C R}^{2}$ & $\mathbf{D i m}^{3}$ & $\mathbf{A V E}^{4}$ & $\mathbf{M S V}^{5}$ \\
\hline Trust & 4 & 0,925 & 0,947 & 1 & 0,816 & 0,579 \\
\hline Quality & 1 & 1,000 & 1,000 & 1 & 1,000 & 0,659 \\
\hline Value & 4 & 0,919 & 0,943 & 1 & 0,806 & 0,176 \\
\hline Satisfaction & 19 & 0,960 & 0,964 & 1 & 0,585 & 0,659 \\
\hline Loyalty & 4 & 0,904 & 0,934 & 1 & 0,776 & 0,176 \\
\hline \hline & ${ }^{1}$ Cronbach's alpha, ${ }^{2}$ Composite Reliability, ${ }^{3}$ Dimensionality, ${ }^{4}$ Variance
\end{tabular}

Extracted, ${ }^{5}$ Maximum Share Variance.

For the constructs, the Cronbach's alpha (CA) and composite reliability (CR) indices had values above 0.60 , in which the required levels of reliability were reached for all constructs. Using Kaiser's criterion, all the constructs are one-dimensional. There is convergent validation in all constructs, as they all have an average variance extracted (AVE) greater than 0.40. According to Fornell's criterion [39], there is discriminant validation in all constructs, except for the satisfaction construct, given that the maximum shared variances (MSV) are lower than the respective AVE. Using cross-factor loadings [44], the satisfaction construct reaches the discriminant validation criterion, as the factor loadings of the items are higher than their respective maximum cross-factor loadings.

For the measurement model of structural equation modeling based on covariance (CB-SEM), it is necessary to test the normality of the data using the Shapiro-Wilk test $(p$-value $<0.05)$ [69]. In this analysis, the data are considered to be non-normal and proceed with the analysis in this approach. The method of Satorra and Bentler [70] was used to create estimators for the covariance structure in the confirmatory factor analysis. The dimensionality, reliability, and convergent validity were verified by analyzing the constructs'quality and validity. The Kaiser criterion [38] was used to verify the dimensionality 
Table 8. Cross-factor loadings of the general measurement model for the modeling of structural equations based on partial least squares.

\begin{tabular}{|c|c|c|c|}
\hline Construct & Item & $\mathbf{F L}^{1}$ & $\operatorname{Max}(\mathrm{CFL})^{2}$ \\
\hline \multirow{4}{*}{ Trust } & CON1 & 0,894 & 0,674 \\
\hline & CON2 & 0,911 & 0,683 \\
\hline & CON3 & 0,904 & 0,707 \\
\hline & CON4 & 0,904 & 0,685 \\
\hline Quality & QUA1 & 1,000 & 0,812 \\
\hline \multirow{4}{*}{ Value } & VAL1 & 0,838 & 0,389 \\
\hline & VAL2 & 0,911 & 0,367 \\
\hline & VAL3 & 0,925 & 0,381 \\
\hline & VAL4 & 0,914 & 0,372 \\
\hline \multirow{19}{*}{ Satisfaction } & SAT1 & 0,720 & 0,631 \\
\hline & SAT2 & 0,755 & 0,619 \\
\hline & SAT3 & 0,754 & 0,604 \\
\hline & SAT4 & 0,811 & 0,651 \\
\hline & SAT5 & 0,771 & 0,606 \\
\hline & SAT6 & 0,765 & 0,617 \\
\hline & SAT7 & 0,740 & 0,570 \\
\hline & SAT8 & 0,831 & 0,665 \\
\hline & SAT9 & 0,765 & 0,592 \\
\hline & SAT10 & 0,771 & 0,629 \\
\hline & SAT11 & 0,665 & 0,534 \\
\hline & SAT12 & 0,796 & 0,638 \\
\hline & SAT13 & 0,838 & 0,673 \\
\hline & SAT14 & 0,758 & 0,603 \\
\hline & SAT15 & 0,792 & 0,648 \\
\hline & SAT16 & 0,766 & 0,608 \\
\hline & SAT17 & 0,770 & 0,623 \\
\hline & SAT18 & 0,762 & 0,647 \\
\hline & SAT19 & 0,689 & 0,653 \\
\hline \multirow{4}{*}{ Loyalty } & FID1 & 0,804 & 0,475 \\
\hline & FID2 & 0,894 & 0,392 \\
\hline & FID3 & 0,914 & 0,368 \\
\hline & FID4 & 0,908 & 0,372 \\
\hline
\end{tabular}

of the constructs. To verify the convergent validity, the criterion proposed by Fornell and Larcker [39] was used, which indicates convergent validation when the AVE is greater than $50 \%$ [40] or $40 \%$ in the case of exploratory research [41]. To measure reliability, the CA and CR were used [42]. For discriminant validity, the criterion of Fornell and Larcker [39] is used, which guarantees discriminant validity when the AVE of a given construct is greater than the shared variance of this construct with the others.

The cross-factor loading method [44] was used to verify discriminant validation. According to Hair et al. [24], items with factor loadings less than 0.50 should be eliminated, as they do not contribute significantly to the formation of the latent variable; they impair the reach of the basic assumptions for validity and quality of the indicators calcultated to represent the concept of interest. Table 9 shows the weights, factor loadings, and commonalities of the items of the constructs in general, indicating that all items have a significant weight and factor loadings above 0.50 . The analysis of convergent validity, discriminant validity, and reliability of the constructs of the general model of structural equation modeling based on covariance are shown in Tables 10 and 11.

In all constructs, the $\mathrm{CA}$ and $\mathrm{CR}$ indices had values above 0.60 , reaching the level of reliability for all constructs. According to Kaiser's criterion, all constructs were onedimensional, with convergent validation in all constructs. All constructs have an AVE greater than 0.40 and, according to the Fornell and Larcker criterion, there is discriminant validation in all constructs, with the exception of the satisfaction construct, given that the maximum shared variances were lower than the respective AVE. Using the method of cross-factor loadings, the satisfaction construct reached the discriminant validation criterion, as the factor loadings of the items were higher than their respective maximum cross-factor loadings.

\subsection{Structural Model}

To verify the quality of the adjustments of structural equation modeling based on partial least squares (PLS-SEM), the coefficient of determination $\left(R^{2}\right)$ and goodness of fit 
Table 9. General measurement model for the modeling of structural equations based on covariance.

\begin{tabular}{|c|c|c|c|c|c|}
\hline Construct & Item & Weight & $p$-value & $\mathbf{F L ^ { I }}$ & Com. $^{2}$ \\
\hline \multirow{4}{*}{ Trust } & TRU1 & 1,000 & - & 0,853 & 0,728 \\
\hline & TRU2 & 1,084 & 0,000 & 0,880 & 0,775 \\
\hline & TRU3 & 1,008 & 0,000 & 0,872 & 0,761 \\
\hline & TRU4 & 1,031 & 0,000 & 0,870 & 0,756 \\
\hline Quality & QUA1 & 1,000 & - & 1,000 & 1,000 \\
\hline \multirow{4}{*}{ Value } & VAL1 & 1,000 & - & 0,749 & 0,561 \\
\hline & VAL2 & 1,217 & 0,000 & 0,875 & 0,765 \\
\hline & VAL3 & 1,247 & 0,000 & 0,920 & 0,846 \\
\hline & VAL4 & 1,205 & 0,000 & 0,898 & 0,807 \\
\hline \multirow{19}{*}{ Satisfaction } & SAT1 & 1,000 & - & 0,700 & 0,491 \\
\hline & SAT2 & 1,015 & 0,000 & 0,737 & 0,543 \\
\hline & SAT3 & 1,014 & 0,000 & 0,735 & 0,540 \\
\hline & SAT4 & 1,134 & 0,000 & 0,801 & 0,641 \\
\hline & SAT5 & 1,110 & 0,000 & 0,758 & 0,574 \\
\hline & SAT6 & 1,015 & 0,000 & 0,752 & 0,565 \\
\hline & SAT7 & 1,068 & 0,000 & 0,723 & 0,523 \\
\hline & SAT8 & 1,118 & 0,000 & 0,822 & 0,676 \\
\hline & SAT9 & 1,106 & 0,000 & 0,748 & 0,559 \\
\hline & SAT10 & 1,168 & 0,000 & 0,754 & 0,568 \\
\hline & SAT11 & 0,876 & 0,000 & 0,645 & 0,416 \\
\hline & SAT12 & 1,148 & 0,000 & 0,785 & 0,616 \\
\hline & SAT13 & 1,167 & 0,000 & 0,833 & 0,694 \\
\hline & SAT14 & 1,167 & 0,000 & 0,743 & 0,552 \\
\hline & SAT15 & 1,057 & 0,000 & 0,781 & 0,610 \\
\hline & SAT16 & 1,105 & 0,000 & 0,749 & 0,561 \\
\hline & SAT17 & 1,117 & 0,000 & 0,754 & 0,569 \\
\hline & SAT18 & 1,018 & 0,000 & 0,747 & 0,558 \\
\hline & SAT19 & 0,883 & 0,000 & 0,671 & 0,451 \\
\hline \multirow{4}{*}{ Loyalty } & LOY1 & 1,000 & - & 0,618 & 0,381 \\
\hline & LOY2 & 1,569 & 0,000 & 0,858 & 0,737 \\
\hline & LOY3 & 1,762 & 0,000 & 0,952 & 0,907 \\
\hline & LOY4 & 1,719 & 0,000 & 0,928 & 0,862 \\
\hline
\end{tabular}

Table 10. Validation of the general measurement model for structural equation modeling based on covariance.

\begin{tabular}{ccccccc}
\hline Construct & Item & $\mathbf{C A}^{1}$ & $\mathbf{C R}^{2}$ & $\mathbf{D i m}^{3}$ & $\mathbf{A V E}^{4}$ & $\mathbf{M S V}^{5}$ \\
\hline Trust & 4 & 0,925 & 0,925 & 1 & 0,755 & 0,681 \\
\hline Quality & 1 & 1,000 & 1,000 & 1 & 1,000 & 0,694 \\
\hline Value & 4 & 0,919 & 0,921 & 1 & 0,740 & 0,034 \\
\hline Satisfaction & 19 & 0,960 & 0,961 & 1 & 0,561 & 0,694 \\
\hline Loyalty & 4 & 0,906 & 0,910 & 1 & 0,704 & 0,187 \\
\hline \hline
\end{tabular}

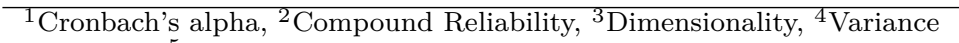
Extracted, ${ }^{5}$ Maximum Shared Variance.

(GoF) indices were used [47]. The value of $R^{2}$ for scale from $0 \%$ to $100 \%$ represents the extent to which the independent constructs explain the dependents, while, values less than $25 \%$ represent weak explanatory capacity, values between $25 \%$ and $50 \%$ indicate moderate explanatory capacity, and values above $50 \%$ define the explanatory capacity [48]. The GoF is the geometric mean of the AVEs of the constructs and $R^{2}$ of the model and varies from $0 \%$ to $100 \%$. The GoF in PLS-SEM cannot discriminate valid from invalid models, in addition to not being applied to models with formative constructs [49]. However, it allows for the synthesis of the AVE and $R^{2}$ of the model in a single statistic, and is useful for future comparisons of the adherence of different samples to the model. The results obtained for the structural model using PLS-SEM are presented in Table 12 and Figure 4. 
Table 11. Cross-factor loadings of the general measurement model for structural equation modeling based on covariance.

\begin{tabular}{|c|c|c|c|}
\hline Construct & Item & $\mathbf{F} \mathbf{L}^{1}$ & $\operatorname{Max}(\mathbf{S F L})^{2}$ \\
\hline \multirow{4}{*}{ Trust } & CON1 & 0,853 & 0,682 \\
\hline & $\mathrm{CON} 2$ & 0,880 & 0,691 \\
\hline & CON3 & 0,872 & 0,708 \\
\hline & CON4 & 0,870 & 0,692 \\
\hline Quality & QUA1 & 1,000 & 0,829 \\
\hline \multirow{4}{*}{ Value } & VAL1 & 0,749 & 0,372 \\
\hline & VAL2 & 0,875 & 0,338 \\
\hline & VAL3 & 0,920 & 0,351 \\
\hline & VAL4 & 0,898 & 0,344 \\
\hline \multirow{19}{*}{ Satisfaction } & SAT1 & 0,700 & 0,637 \\
\hline & SAT2 & 0,737 & 0,621 \\
\hline & SAT3 & 0,735 & 0,611 \\
\hline & SAT4 & 0,801 & 0,662 \\
\hline & SAT5 & 0,758 & 0,633 \\
\hline & SAT6 & 0,752 & 0,644 \\
\hline & SAT7 & 0,723 & 0,599 \\
\hline & SAT8 & 0,822 & 0,671 \\
\hline & SAT9 & 0,748 & 0,612 \\
\hline & SAT10 & 0,754 & 0,652 \\
\hline & SAT11 & 0,645 & 0,579 \\
\hline & SAT12 & 0,785 & 0,650 \\
\hline & SAT13 & 0,833 & 0,680 \\
\hline & SAT14 & 0,743 & 0,628 \\
\hline & SAT15 & 0,781 & 0,666 \\
\hline & SAT16 & 0,749 & 0,622 \\
\hline & SAT17 & 0,754 & 0,633 \\
\hline & SAT18 & 0,747 & 0,665 \\
\hline & SAT19 & 0,671 & 0,657 \\
\hline \multirow{4}{*}{ Loyalty } & FID1 & 0,618 & 0,480 \\
\hline & FID2 & 0,858 & 0,377 \\
\hline & FID3 & 0,952 & 0,375 \\
\hline & FID4 & 0,928 & 0,380 \\
\hline
\end{tabular}

Table 12. Quantitative description of the general structural model for structural equation modeling based on partial least squares.

\begin{tabular}{ccccccc}
\hline Endogenous & Exogenous & $\beta$ & SE $\left(\beta^{1}\right)$ & CI $-\mathbf{9 5 \%} \mathbf{F}^{2}$ & $p$-value & $R^{2}$ \\
\hline Quality & Trust & 0,672 & 0,003 & {$[0,669 ; 0,676]$} & $<0,001$ & $45,2 \%$ \\
\hline Value & Quality & $-0,238$ & 0,003 & {$[-0,243 ;-0,230]$} & $<0,001$ & $5,7 \%$ \\
\hline \multirow{2}{*}{ Satisfaction } & Trust & 0,391 & 0,002 & {$[0,384 ; 0,397]$} & $<0,001$ & \\
& Quality & 0,548 & 0,002 & {$[0,543 ; 0,554]$} & $<0,001$ & $74,4 \%$ \\
& Value & $-0,007$ & 0,002 & {$[-0,010 ;-0,004]$} & $<0,001$ & \\
\hline \multirow{2}{*}{ Loyalty } & Trust & 0,346 & 0,005 & {$[0,338 ; 0,356]$} & $<0,001$ & $21,8 \%$ \\
& Satisfaction & 0,146 & 0,005 & {$[0,136 ; 0,155]$} & $<0,001$ & \\
\hline \hline
\end{tabular}

${ }^{1}$ Standard Error; ${ }^{2}$ confidence interval; GoF $=49,6 \%$.

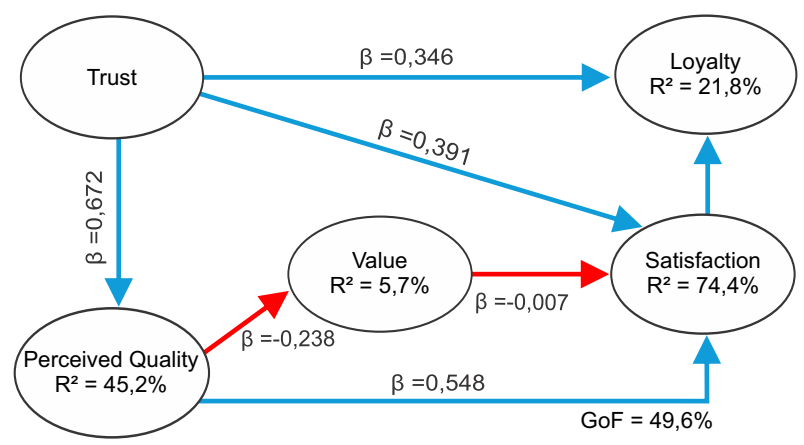

Figure 4. General structural model for modeling structural equations based on partial least squares.

With Table 12 and Figure 4 in hand, it is possible to carry out the analysis using the constructs. The trust construct explains $45.2 \%$ of the variability in the quality construct, resulting in moderate explanatory power. The influence occurs with a $p$-value $<0.001$ and positive with $\beta=0.672[0.669 ; 0.676]$ of the trust construct over the quality construct, indicating that the greater the trust, the greater the quality. The quality construct explains 
$5.7 \%$ of the variability in the value construct, indicating a weak explanatory capacity. The value construct has an influence with a $p$-value $<0.001$ and negative with $\beta=-0.238$ $[-0.243 ;-0.23]$ of the quality construct over the value construct, indicating that the higher the quality, the lower the perception that the amount paid in energy bills is high.

There is an influence of the trust construct on the satisfaction construct with $p$-value $<0.001$ and positive with $\beta=0.391$ [0.384; 0.397], indicating that the greater the trust, the greater the satisfaction. The influence measured between the quality construct on the satisfaction construct has a $p$-value $<0.001$ and positive with $\beta=0.548[0.543 ; 0.554]$, indicating that the higher the quality, the greater the satisfaction. There is also the influence of the value construct on the satisfaction construct with $p$-value $<0.001$ and negative with $\beta=-0.007[-0.01 ;-0.004]$, indicating that the higher the amount paid on energy bills, the lower the satisfaction. The trust, quality, and value constructs explain $74.4 \%$ of the variability of the satisfaction construct, indicating substantial explanatory capacity.

Regarding loyalty, there was a significant influence of trust with $p$-value $<0.001$ and positive with $\beta=0.346[0.338 ; 0.356]$. Thus, the greater the trust, the greater the loyalty. There was also an influence of the satisfaction construct on the loyalty construct with $p$-value $<0.001$ and positive with $\beta=0.146[0.136 ; 0.155]$. Trust and satisfaction were able to explain $21.8 \%$ of the variability in loyalty; that is, there was weak explanatory capacity. The model presented a GoF of $49.6 \%$ and the bootstrap confidence intervals agreed with the results obtained via the $p$-value, indicating greater validity of the results.

To verify the quality of fits in structural equation modeling based on covariance (CBSEM), as well as in PLS-SEM, the $R^{2}$ was used. However, unlike PLS-SEM, CB-SEM still uses the comparative fit index (CFI), Tucker Lewis index (TLI) and mean squared error of approximation (RMSEA) in addition to the $p$-value to check if the RMSEA is statistically greater than 0.05. In this work, CFI and TLI are expected to be greater than 0.80 [67], and the RMSEA is less than 0.10 [68], ideally $\leq 0.05$. The results of the structural model using CB-SEM are shown in Table 13 and shown in Figure 5.

Table 13. Quantitative description of the general structural model for structural equation modeling based on covariance.

\begin{tabular}{ccccccc}
\hline Endogenous & Exogenous & $\beta$ & SE $\left(\beta^{1}\right)$ & CI $-\mathbf{9 5 \%}^{2}$ & $p$-value & $R^{2}$ \\
\hline Quality & Trust & 0,811 & 0,004 & {$[0,803 ; 0,819]$} & $<0,001$ & $48,8 \%$ \\
\hline Value & Quality & $-0,175$ & 0,003 & {$[-0,181 ;-0,169]$} & $<0,001$ & $6,0 \%$ \\
\hline \multirow{2}{*}{ Satisfaction } & Trust & 0,387 & 0,003 & {$[0,381 ; 0,393]$} & $<0,001$ & \\
& Quality & 0,393 & 0,003 & {$[0,387 ; 0,399]$} & $<0,001$ & $77,7 \%$ \\
& Value & 0,001 & 0,002 & {$[-0,003 ; 0,005]$} & 0,509 & \\
\hline Loyalty & Trust & 0,308 & 0,005 & {$[0,298 ; 0,318]$} & $<0,001$ & $18,2 \%$ \\
& Satisfaction & 0,063 & 0,006 & {$[0,051 ; 0,075]$} & $<0,001$ & \\
\hline \hline
\end{tabular}

${ }^{1}$ Standard Error; ${ }^{2}$ Confidence interval.

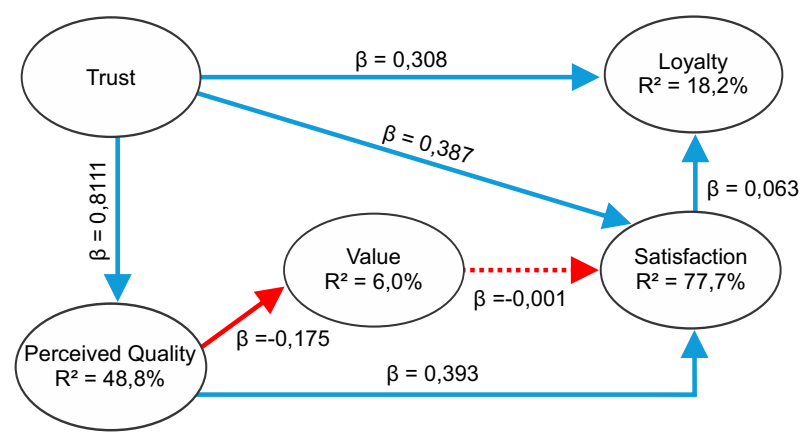

Figure 5. General structural model for the modeling of structural equations based on covariance.

Regarding quality, there was an influence of the trust construct with $p$-value $<0.001$ and positive with $\beta=0.811$. Therefore, the greater the trust, the greater is the quality. Trust explained $48.8 \%$ of the variability in quality, with moderate explanatory power. The value construct was influenced by the quality construct with $p$-value $<0.001$ and 
negative with $\beta=-0.175$, so the higher the quality, the higher the value. The quality explained $6.0 \%$ of the variability in value, that is, there was a low explanatory capacity.

Regarding satisfaction, there was a significant and positive influence of the trust construct with $p$-value $<0.001$ and $\beta=0.387$; thus, the greater the trust, the greater the satisfaction. There was also a significant and positive influence of quality on satisfaction, with $p$-value $<0.001$ and $\beta=0.393$, so the higher the quality, the greater the satisfaction. Finally, there was no significant influence of value on satisfaction. The trust, quality, and value constructs together explained $77.7 \%$ of the variability in satisfaction, that is, there was substantial explanatory capacity.

For the loyalty construct, there was a significant influence of the trust construct with $p$-value $<0.001$ and positive with $\beta=0.308$, so the greater the trust, the greater the loyalty. Regarding satisfaction with loyalty, there was a significant difference with $p$-value $<0.001$ and positive with $\beta=0.063$, that is, the greater the satisfaction, the greater the loyalty. Finally, trust and satisfaction were able to explain $18.2 \%$ of the variability in loyalty, with weak explanatory capacity.

Table 14 shows the measures of the goodness of fit for the general CB-SEM model. The values indicate that the general model is satisfactory with values of CFI and TLI $\geq 0.80$ and $\mathrm{RMSEA} \leq 0.10$, with $p$-value $\leq 0,05$.

Table 14. Result of the adjustment of the structural model for the modeling of structural equations based on covariance.

\begin{tabular}{rccc}
\hline CFI & TLI & RMSEA & $p$-value \\
\hline 0,933 & 0,928 & 0,054 & $<0,001$ \\
\hline \hline
\end{tabular}

\subsection{Multigroup Analysis}

To compare the relationships between the constructs using PLS-SEM, a multigroup analysis was performed in each group (Group 1, Group 2, and Group 3). Thus, models were adjusted for each group, and the results of these models were compared. Table 15 shows the $p$-values of the multigroup analysis for the weights of the measurement models per group. If the comparison between the weights of a given item has a significant difference, that is, $p$-value $<0.050$ in any of the groups, there is evidence that the perception of that concept has changed between the groups.

The analysis of convergent validity, discriminant validity, dimensionality, and reliability of the constructs in the measurement models of the groups are shown in Tables 16 and 17. In the measurement models of the three groups, all constructs presented CA and/or $\mathrm{CR}$ values greater than 0.60 , indicating the reliability of the models. All constructs were one-dimensional according to Kaiser's criterion [38] and all reached convergent validation, as the AVEs were above 0.40. The trust, quality, value, and loyalty constructs reached discriminant validation according to Fornell's criterion [39] for the three models, since the maximum shared variances were lower than the respective AVEs. However, the satisfaction construct did not reach discriminant validation by Fornell's criterion [39] in any of the groups, but there was discriminant validation of this construct in the three groups according to the criterion of factor loadings, because the factor loadings of the items were greater than their respective maximum cross-factor loadings.

Tables 18, 19, and 20 display the results, Figure 6, Figure 7, and Figure 8 present the structural models and Table 21 displays the $p$-values of the multigroup analysis for the coefficients, all for each group using PLS-SEM.

The multigroup analysis indicated that there was no significant difference in the influence of trust on quality between the three groups $(p$-value $>0.050)$. However, there was a significant difference in the influence of quality on value with $p$-value $=0,049$ in the comparison between Group 2 and Group 3, in which the strength of the influence of quality on the value construct was lower in Group 3, as follows: Group 2 with $\beta=-0.220$ and Group 3 with $\beta=-0.236$. Regarding trust in satisfaction constructs, there was no 
Table 15. Weights of the multigroup analysis of the measurement model of structural equation modeling based on partial least squares.

\begin{tabular}{|c|c|c|c|c|}
\hline Construct & Item & $\begin{array}{c}\text { Group } 1 \\
x \\
\text { Group } 2\end{array}$ & $\begin{array}{c}\text { Group } 1 \\
x \\
\text { Group } 3\end{array}$ & $\begin{array}{c}\text { Group } 2 \\
x \\
\text { Group } 3\end{array}$ \\
\hline \multirow{4}{*}{ Trust } & $\overline{\mathrm{CON} 1}$ & $<<0,520$ & $\overline{0,063}$ & $\overline{0,206}$ \\
\hline & $\mathrm{CON} 2$ & 0,013 & 0,000 & 0,085 \\
\hline & CON3 & 0,165 & 0,003 & 0,000 \\
\hline & CON4 & $<0,849$ & 0,414 & 0,309 \\
\hline \multirow{4}{*}{ Value } & VAL1 & 0,552 & $<0,467$ & 0,811 \\
\hline & VAL2 & 0,384 & 0,029 & 0,114 \\
\hline & VAL3 & 0,109 & 0,006 & 0,000 \\
\hline & VAL4 & 0,032 & 0,028 & 0,000 \\
\hline \multirow{19}{*}{ Satisfaction } & SAT1 & 0,078 & 0,004 & 0,000 \\
\hline & SAT2 & 0,394 & 0,170 & 0,026 \\
\hline & SAT3 & 0,413 & 0,984 & 0,441 \\
\hline & SAT4 & 0,230 & 0,191 & 0,011 \\
\hline & SAT5 & 0,431 & 0,414 & 0,080 \\
\hline & SAT6 & 0,012 & 0,697 & 0,008 \\
\hline & SAT7 & 0,425 & 0,254 & 0,657 \\
\hline & SAT8 & 0,070 & 0,000 & 0,000 \\
\hline & SAT9 & 0,350 & 0,001 & 0,000 \\
\hline & SAT10 & 0,886 & 0,001 & 0,001 \\
\hline & SAT11 & 0,084 & 0,883 & 0,132 \\
\hline & SAT12 & 0,412 & 0,223 & 0,029 \\
\hline & SAT13 & 0,002 & 0,003 & 0,000 \\
\hline & SAT14 & 0,401 & 0,682 & 0,736 \\
\hline & SAT15 & 0,003 & 0,000 & 0,080 \\
\hline & SAT16 & 0,934 & 0,000 & 0,000 \\
\hline & SAT17 & 0,454 & 0,000 & 0,000 \\
\hline & SAT18 & 0,131 & 0,000 & 0,000 \\
\hline & SAT19 & 0,314 & 0,009 & 0,000 \\
\hline \multirow{4}{*}{ Loyalty } & FID1 & 0,068 & 0,001 & 0,000 \\
\hline & FID2 & 0,861 & 0,009 & 0,006 \\
\hline & FID3 & 0,737 & 0,042 & 0,007 \\
\hline & FID4 & 0,436 & 0,142 & 0,398 \\
\hline
\end{tabular}

Table 16. Validation of measurement models for groups using structural equation modeling based on partial least squares.

\begin{tabular}{|c|c|c|c|c|c|c|c|}
\hline & Construct & Item & $\mathbf{C A}^{1}$ & $\mathbf{C R}^{2}$ & $\operatorname{Dim}^{3}$ & $\mathbf{A V E}^{4}$ & MSV $^{5}$ \\
\hline \multirow{5}{*}{ Group 1} & Trust & 4 & 0,928 & 0,948 & 1 & 0,822 & 0,587 \\
\hline & Quality & 1 & 1,000 & 1,000 & 1 & 1,000 & 0,676 \\
\hline & Value & 4 & 0,912 & 0,939 & 1 & 0,793 & 0,056 \\
\hline & Satisfaction & 19 & 0,961 & 0,965 & 1 & 0,591 & 0,676 \\
\hline & Loyalty & 4 & 0,903 & 0,933 & 1 & 0,773 & 0,206 \\
\hline \multirow{5}{*}{ Group 2} & Trust & 4 & 0,926 & 0,948 & 1 & 0,819 & 0,569 \\
\hline & Quality & 1 & 1,000 & 1,000 & 1 & 1,000 & 0,646 \\
\hline & Value & 4 & 0,932 & 0,951 & 1 & 0,830 & 0,048 \\
\hline & Satisfaction & 19 & 0,962 & 0,965 & 1 & 0,593 & 0,646 \\
\hline & Loyalty & 4 & 0,908 & 0,937 & 1 & 0,785 & 0,203 \\
\hline \multirow{5}{*}{ Group 3} & Trust & 4 & 0,918 & 0,942 & 1 & 0,803 & 0,567 \\
\hline & Quality & 1 & 1,000 & 1,000 & 1 & 1,000 & 0,651 \\
\hline & Value & 4 & 0,907 & 0,935 & 1 & 0,783 & 0,056 \\
\hline & Satisfaction & 19 & 0,957 & 0,961 & 1 & 0,565 & 0,651 \\
\hline & Loyalty & 4 & 0,894 & 0,928 & 1 & 0,756 & 0,191 \\
\hline
\end{tabular}

significant difference in influence between groups with a $p$-value $>0.050$. Regarding the quality over satisfaction constructs, there was a significant difference $(p$-value $=0.002)$ in the comparison between Group 1 and Group 2, with the strength of influence of quality on satisfaction being higher in Group $1(\beta=0.559)$ and Group $2(\beta=0.542)$.

There was also no significant difference in the influence of trust on loyalty between the three groups, with a $p$-value $>0.050$ and finally, there was no significant difference in the influence of satisfaction on loyalty between the three groups ( $p$-value $>0.050)$. As there were significant different weights between the years analyzed (2014 - 2018) for all constructs, with the exception of for the quality construct, the significant difference between the structural coefficients may have been caused by the significant differences between the weights. The models presented GoFs equal to $49.9 \%, 49.3 \%$ and $48.2 \%$ for Group 1, Group 2, and Group 3, respectively. 
Table 17. Cross-factor loadings of group models using structural equation modeling based on partial least squares.

\begin{tabular}{|c|c|c|c|c|c|c|c|}
\hline \multirow[t]{2}{*}{ Construct } & \multirow[t]{2}{*}{ Item } & \multicolumn{2}{|c|}{ Group 1} & \multicolumn{2}{|c|}{ Group 2} & \multicolumn{2}{|c|}{ Group 3} \\
\hline & & $\mathbf{F} \mathbf{L}^{1}$ & $\begin{array}{c}\operatorname{Max} \\
(\text { CFL })^{2}\end{array}$ & $\mathbf{F L}^{1}$ & $\begin{array}{c}\text { Max } \\
(\text { CFL })^{2}\end{array}$ & $\mathbf{F L}^{1}$ & $\begin{array}{c}\operatorname{Max} \\
(\text { CFL })^{2}\end{array}$ \\
\hline \multirow{4}{*}{ Trust } & TRU1 & 0,898 & 0,679 & 0,895 & 0,671 & 0,887 & 0,661 \\
\hline & TRU2 & 0,911 & 0,685 & 0,915 & 0,682 & 0,904 & 0,668 \\
\hline & TRU3 & 0,908 & 0,717 & 0,905 & 0,697 & 0,896 & 0,699 \\
\hline & TRU4 & 0,909 & 0,697 & 0,904 & 0,680 & 0,897 & 0,670 \\
\hline Quality & QUA1 & 1,000 & 0,822 & 1,000 & 0,804 & 1,000 & 0,807 \\
\hline \multirow{4}{*}{ Value } & VAL1 & 0,819 & 0,383 & 0,863 & 0,389 & 0,810 & 0,354 \\
\hline & VAL2 & 0,909 & 0,357 & 0,923 & 0,382 & 0,898 & 0,332 \\
\hline & VAL3 & 0,921 & 0,371 & 0,933 & 0,391 & 0,921 & 0,351 \\
\hline & VAL4 & 0,909 & 0,357 & 0,924 & 0,387 & 0,907 & 0,343 \\
\hline \multirow{19}{*}{ Satisfaction } & SAT1 & 0,727 & 0,646 & 0,715 & 0,618 & 0,714 & 0,627 \\
\hline & SAT2 & 0,764 & 0,632 & 0,758 & 0,620 & 0,736 & 0,596 \\
\hline & SAT3 & 0,754 & 0,613 & 0,763 & 0,604 & 0,737 & 0,586 \\
\hline & SAT4 & 0,816 & 0,668 & 0,817 & 0,649 & 0,795 & 0,631 \\
\hline & SAT5 & 0,775 & 0,622 & 0,778 & 0,602 & 0,757 & 0,589 \\
\hline & SAT6 & 0,777 & 0,630 & 0,764 & 0,614 & 0,750 & 0,600 \\
\hline & SAT7 & 0,744 & 0,581 & 0,748 & 0,571 & 0,725 & 0,555 \\
\hline & SAT8 & 0,834 & 0,680 & 0,833 & 0,654 & 0,823 & 0,659 \\
\hline & SAT9 & 0,766 & 0,600 & 0,770 & 0,590 & 0,754 & 0,580 \\
\hline & SAT10 & 0,775 & 0,637 & 0,775 & 0,630 & 0,757 & 0,612 \\
\hline & SAT11 & 0,667 & 0,538 & 0,682 & 0,543 & 0,640 & 0,515 \\
\hline & SAT12 & 0,803 & 0,654 & 0,801 & 0,638 & 0,777 & 0,614 \\
\hline & SAT13 & 0,843 & 0,688 & 0,839 & 0,666 & 0,829 & 0,659 \\
\hline & SAT14 & 0,763 & 0,617 & 0,770 & 0,610 & 0,733 & 0,576 \\
\hline & SAT15 & 0,792 & 0,653 & 0,802 & 0,655 & 0,777 & 0,630 \\
\hline & SAT16 & 0,764 & 0,614 & 0,774 & 0,603 & 0,755 & 0,599 \\
\hline & SAT17 & 0,765 & 0,626 & 0,774 & 0,619 & 0,765 & 0,616 \\
\hline & SAT18 & 0,762 & 0,647 & 0,769 & 0,646 & 0,751 & 0,644 \\
\hline & SAT19 & 0,692 & 0,669 & 0,680 & 0,639 & 0,689 & 0,646 \\
\hline \multirow{4}{*}{ Loyalty } & $\begin{array}{l}\text { LOY1 } \\
\end{array}$ & 0,807 & 0,473 & 0,807 & 0,470 & 0,799 & 0,460 \\
\hline & LOY2 & 0,891 & 0,386 & 0,898 & 0,391 & 0,884 & 0,364 \\
\hline & LOY3 & 0,911 & 0,365 & 0,920 & 0,367 & 0,899 & 0,335 \\
\hline & LOY4 & 0,905 & 0,370 & 0,914 & 0,373 & 0,892 & 0,341 \\
\hline
\end{tabular}

${ }^{1}$ Factorial Loading; ${ }^{2}$ Maximum Cross-Factor Loading

Table 18. Structural model for Group 1 using structural equation modeling based on partial least squares.

\begin{tabular}{ccccccc}
\hline Endogenous & Exogenous & $\beta$ & SE $\left(\beta^{1}\right)$ & $\mathbf{C I}-\mathbf{9 5 \%} \mathbf{\%}^{2}$ & $p$-value & $R^{2}$ \\
\hline Quality & Trust & 0,675 & 0,005 & {$[0,667 ; 0,683]$} & 0,000 & $45,5 \%$ \\
\hline Value & Quality & $-0,236$ & 0,006 & {$[-0,249 ;-0,223]$} & 0,000 & $5,6 \%$ \\
\hline \multirow{2}{*}{ Satisfaction } & Trust & 0,388 & 0,004 & {$[0,376 ; 0,397]$} & 0,000 & \\
& Quality & 0,559 & 0,004 & {$[0,551 ; 0,571]$} & 0,000 & $75,8 \%$ \\
& Value & $-0,004$ & 0,003 & {$[-0,010 ; 0,001]$} & 0,172 & \\
\hline Loyalty & Trust & 0,345 & 0,009 & {$[0,327 ; 0,360]$} & 0,000 & $21,5 \%$ \\
& Satisfaction & 0,143 & 0,009 & {$[0,127 ; 0,162]$} & 0,000 & \\
\hline \hline
\end{tabular}

${ }^{1}$ Standard Error; ${ }^{2}$ Confidence interval; GoF $=49,9 \%$.

Table 19. Structural model for Group 2 using structural equation modeling based on partial least squares.

\begin{tabular}{ccccccc}
\hline Endogenous & Exogenous & $\beta$ & SE $\left(\beta^{1}\right)$ & $\mathbf{C I}-\mathbf{9 5 \%} \mathbf{\%}^{2}$ & $p$-value & $R^{2}$ \\
\hline Quality & Trust & 0,665 & 0,004 & {$[0,657 ; 0,673]$} & 0,000 & $44,3 \%$ \\
\hline Value & Quality & $-0,220$ & 0,005 & {$[-0,230 ;-0,210]$} & 0,000 & $4,8 \%$ \\
\hline \multirow{2}{*}{ Satisfaction } & Trust & 0,391 & 0,004 & {$[0,382 ; 0,401]$} & 0,000 & \\
& Quality & 0,542 & 0,004 & {$[0,532 ; 0,549]$} & 0,000 & $73,3 \%$ \\
& Value & $-0,011$ & 0,003 & {$[-0,017 ;-0,006]$} & 0,000 & \\
\hline \multirow{2}{*}{ Loyalty } & Trust & 0,341 & 0,008 & {$[0,326 ; 0,356]$} & 0,000 & $21,2 \%$ \\
& Satisfaction & 0,145 & 0,008 & {$[0,127 ; 0,161]$} & 0,000 & \\
\hline \hline
\end{tabular}

${ }^{1}$ Standard Error; ${ }^{2}$ Confidence interval; GoF $=49,3 \%$.

A multigroup analysis was also performed using structural equation modeling based on covariance (CB-SEM) in the three groups. The results of the models of the three groups were compared using metric equivalence analysis. The analysis of convergent validity, discriminant validity, dimensionality and reliability of the constructs of the measurement models of the groups using CB-SEM are shown in Table 22 and Table 23.

In the three measurement models, all constructs had $\mathrm{CA}$ and/or $\mathrm{CR}$ value $\geq 0.60$, indicating the reliability of the models. All constructs were one-dimensional according to 
Table 20. Structural model for Group 3 using structural equation modeling based on partial least squares.

\begin{tabular}{ccccccc}
\hline Endogenous & Exogenous & $\beta$ & SE $\left(\beta^{1}\right)$ & CI $-\mathbf{9 5 \%} \mathbf{\%}^{2}$ & $p$-value & $R^{2}$ \\
\hline Quality & Trust & 0,665 & 0,004 & {$[0,659 ; 0,672]$} & 0,000 & $44,2 \%$ \\
\hline Value & Quality & $-0,236$ & 0,006 & {$[-0,248 ;-0,225]$} & 0,000 & $5,6 \%$ \\
\hline \multirow{2}{*}{ Satisfaction } & Trust & 0,387 & 0,004 & {$[0,376 ; 0,396]$} & 0,000 & \\
& Quality & 0,549 & 0,004 & {$[0,540 ; 0,560]$} & 0,000 & $73,6 \%$ \\
& Value & $-0,004$ & 0,003 & {$[-0,011 ; 0,002]$} & 0,173 & \\
\hline \multirow{2}{*}{ Loyalty } & Trust & 0,330 & 0,008 & {$[0,314 ; 0,345]$} & 0,000 & $20,0 \%$ \\
& Satisfaction & 0,141 & 0,008 & {$[0,123 ; 0,158]$} & 0,000 & \\
\hline \hline
\end{tabular}

${ }^{\mathrm{I}}$ Standard Error; ${ }^{2}$ Confidence interval; GoF $=48,2 \%$.

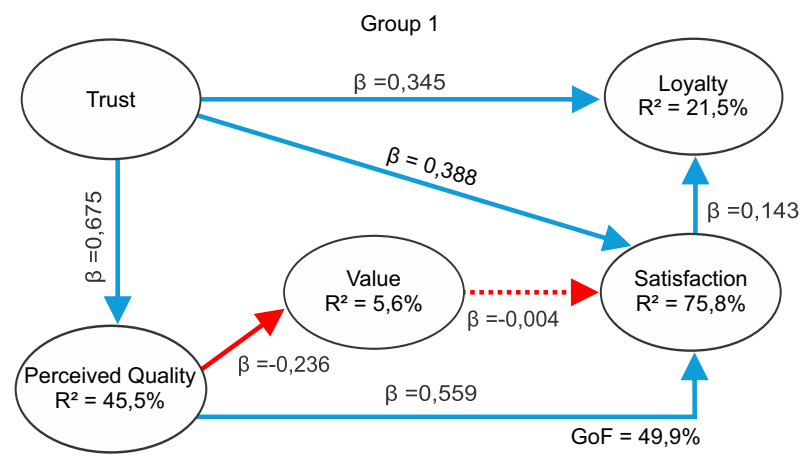

Figure 6. Group 1 structural model using structural equation modeling based on partial least squares.

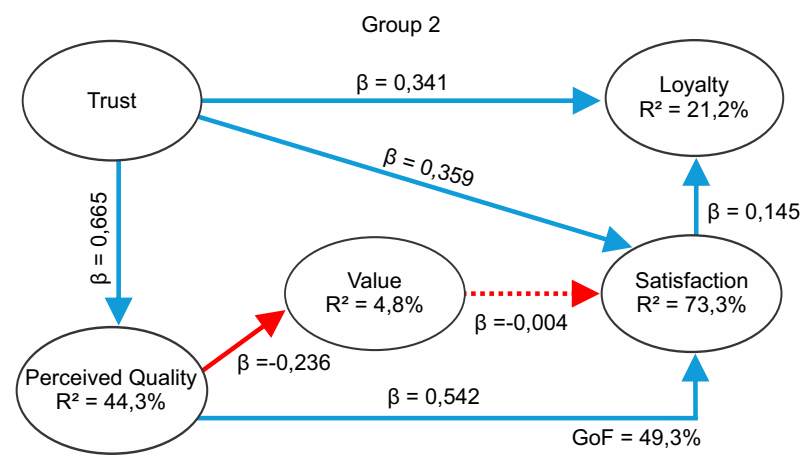

Figure 7. Group 2 structural model using structural equation modeling based on partial least squares.

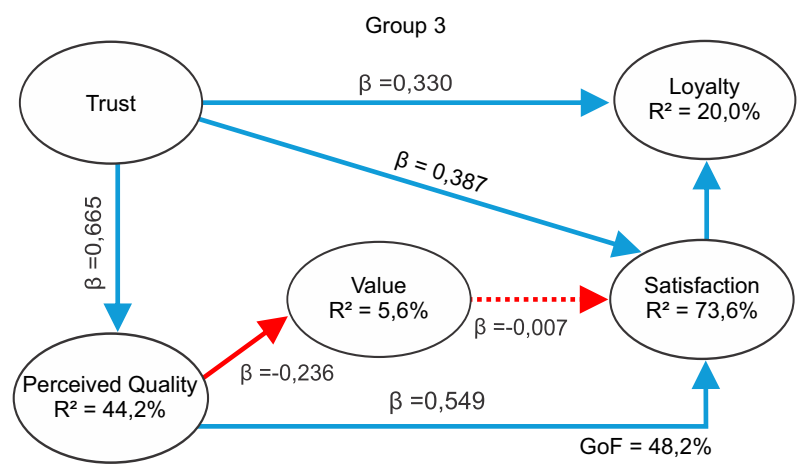

Figure 8. Group 3 structural model using structural equation modeling based on partial least squares.

Kaiser's criterion and all reached convergent validation, as AVE was $\geq 0.40$. The trust, quality, value, and loyalty constructs reached discriminant validation according to the Fornell and Larcker criteria in the group models, since the maximum shared variances were lower than the respective AVEs. However, the satisfaction construct did not reach 
Table 21. Coefficients of the structural model by Group using structural equation modeling based on partial least squares.

\begin{tabular}{ccccc}
\hline Endogenous & Exogenous & $\begin{array}{c}\text { Group 1 } \\
\mathbf{x} \\
\text { Group 2 }\end{array}$ & $\begin{array}{c}\text { Group 1 } \\
\text { Group 3 }\end{array}$ & $\begin{array}{c}\text { Group 2 } \\
\mathbf{x} \\
\text { Group 3 }\end{array}$ \\
\hline Quality & Trust & 0,128 & 0,111 & 0,914 \\
\hline Value & Quality & 0,052 & 0,961 & 0,049 \\
& Trust & 0,579 & 0,848 & 0,440 \\
\hline Satisfaction & Quality & 0,002 & 0,094 & 0,163 \\
& Value & 0,139 & 0,973 & 0,121 \\
\hline Loyalty & Trust & 0,721 & 0,227 & 0,356 \\
& Satisfaction & 0,868 & 0,877 & 0,734 \\
\hline \hline
\end{tabular}

Table 22. Validation of measurement models for groups using structural equation modeling based on covariance.

\begin{tabular}{lccccccc}
\hline & Construct & Item & $\mathbf{C A}^{1}$ & $\mathbf{C R}^{2}$ & $\mathbf{D i m}^{3}$ & $\mathbf{A V E}^{4}$ & $\mathbf{M S V}^{5}$ \\
\hline \multirow{4}{*}{ Group 1 } & Trust & 4 & 0,927 & 0,926 & 1 & 0,758 & 0,679 \\
& Quality & 1 & 1,000 & 1,000 & 1 & 1,000 & 0,697 \\
& Value & 4 & 0,913 & 0,932 & 1 & 0,773 & 0,043 \\
& Satisfaction & 19 & 0,961 & 0,962 & 1 & 0,569 & 0,697 \\
& Loyalty & 4 & 0,905 & 0,915 & 1 & 0,715 & 0,184 \\
\hline \multirow{4}{*}{ Group 2 } & Trust & 4 & 0,926 & 0,926 & 1 & 0,758 & 0,668 \\
& Quality & 1 & 1,000 & 1,000 & 1 & 1,000 & 0,659 \\
& Value & 4 & 0,932 & 0,932 & 1 & 0,773 & 0,032 \\
& Satisfaction & 19 & 0,962 & 0,962 & 1 & 0,569 & 0,668 \\
Group 3 3 & Loyalty & 4 & 0,911 & 0,915 & 1 & 0,715 & 0,177 \\
& Trust & 4 & 0,918 & 0,918 & 1 & 0,737 & 0,680 \\
& Quality & 1 & 1,000 & 1,000 & 1 & 1,000 & 0,687 \\
& Value & 4 & 0,907 & 0,909 & 1 & 0,709 & 0,046 \\
& Satisfaction & 19 & 0,957 & 0,957 & 1 & 0,540 & 0,687 \\
${ }^{1}$ Cronbach's & Loyalty & 4 & 0,896 & 0,900 & 1 & 0,680 & 0,166 \\
\hline
\end{tabular}

Extracted , ${ }^{5}$ Maximum Shared Variance.

Table 23. Cross-factor loadings of group models using structural equation modeling based on partial least squares.

\begin{tabular}{|c|c|c|c|c|c|c|c|}
\hline \multirow[t]{2}{*}{ Construct } & \multirow[t]{2}{*}{ Item } & \multicolumn{2}{|c|}{ Group 1} & \multicolumn{2}{|c|}{ Group 2} & \multicolumn{2}{|c|}{ Group 3} \\
\hline & & $\mathbf{F} \mathbf{L}^{1}$ & $\begin{array}{c}\text { Max } \\
(\text { CFL })^{2}\end{array}$ & $\mathbf{F} \mathbf{L}^{1}$ & $\begin{array}{c}\operatorname{Max} \\
(\mathrm{CFL})^{2}\end{array}$ & $\mathbf{F L}^{1}$ & $\begin{array}{c}\text { Max } \\
(\mathrm{CFL})^{2}\end{array}$ \\
\hline \multirow{4}{*}{ Trust } & TRU1 & 0,857 & 0,682 & 0,855 & 0,679 & 0,842 & 0,670 \\
\hline & TRU2 & 0,878 & 0,688 & 0,886 & 0,688 & 0,869 & 0,678 \\
\hline & TRU3 & 0,879 & 0,714 & 0,874 & 0,696 & 0,862 & 0,703 \\
\hline & TRU4 & 0,878 & 0,699 & 0,869 & 0,684 & 0,860 & 0,680 \\
\hline Quality & QUA1 & 1,000 & 0,835 & 1,000 & 0,822 & 1,000 & 0,827 \\
\hline \multirow{4}{*}{ Value } & VAL1 & 0,719 & 0,369 & 0,790 & 0,369 & 0,710 & 0,340 \\
\hline & VAL2 & 0,870 & 0,332 & 0,892 & 0,352 & 0,855 & 0,302 \\
\hline & VAL3 & 0,917 & 0,343 & 0,925 & 0,363 & 0,915 & 0,319 \\
\hline & VAL4 & 0,893 & 0,331 & 0,910 & 0,359 & 0,887 & 0,312 \\
\hline \multirow{19}{*}{ Satisfaction } & SAT1 & 0,709 & 0,648 & 0,692 & 0,626 & 0,695 & 0,629 \\
\hline & SAT2 & 0,746 & 0,623 & 0,740 & 0,614 & 0,717 & 0,597 \\
\hline & SAT3 & 0,736 & 0,613 & 0,745 & 0,599 & 0,718 & 0,594 \\
\hline & SAT4 & 0,807 & 0,677 & 0,806 & 0,650 & 0,784 & 0,634 \\
\hline & SAT5 & 0,762 & 0,625 & 0,764 & 0,614 & 0,742 & 0,600 \\
\hline & SAT6 & 0,764 & 0,628 & 0,751 & 0,620 & 0,736 & 0,606 \\
\hline & SAT7 & 0,728 & 0,597 & 0,732 & 0,594 & 0,706 & 0,569 \\
\hline & SAT8 & 0,826 & 0,678 & 0,824 & 0,661 & 0,814 & 0,651 \\
\hline & SAT9 & 0,748 & 0,610 & 0,754 & 0,614 & 0,736 & 0,598 \\
\hline & SAT10 & 0,758 & 0,655 & 0,757 & 0,648 & 0,738 & 0,639 \\
\hline & SAT11 & 0,648 & 0,573 & 0,664 & 0,581 & 0,620 & 0,540 \\
\hline & SAT12 & 0,794 & 0,659 & 0,791 & 0,646 & 0,764 & 0,631 \\
\hline & SAT13 & 0,838 & 0,688 & 0,834 & 0,675 & 0,822 & 0,671 \\
\hline & SAT14 & 0,749 & 0,621 & 0,757 & 0,631 & 0,716 & 0,595 \\
\hline & SAT15 & 0,780 & 0,665 & 0,794 & 0,665 & 0,764 & 0,650 \\
\hline & SAT16 & 0,746 & 0,619 & 0,759 & 0,626 & 0,737 & 0,612 \\
\hline & SAT17 & 0,748 & 0,628 & 0,760 & 0,629 & 0,748 & 0,637 \\
\hline & SAT18 & 0,746 & 0,657 & 0,755 & 0,667 & 0,736 & 0,663 \\
\hline & SAT19 & 0,676 & 0,664 & 0,660 & 0,646 & 0,672 & 0,653 \\
\hline \multirow{4}{*}{ Loyalty } & LOY1 & 0,618 & 0,474 & 0,626 & 0,478 & 0,592 & 0,456 \\
\hline & LOY2 & 0,849 & 0,372 & 0,867 & 0,381 & 0,845 & 0,351 \\
\hline & LOY3 & 0,951 & 0,370 & 0,957 & 0,371 & 0,945 & 0,340 \\
\hline & LOY4 & 0,928 & 0,376 & 0,934 & 0,374 & 0,917 & 0,347 \\
\hline
\end{tabular}

${ }^{1}$ Factorial Loading; ${ }^{2}$ Maximum Cross-factor Loading 
discriminant validation by the Fornell and Larcker criteria in any of the groups. According to the factor loadings criterion, there was discriminant validation of the satisfaction construct in the three groups, since the factor loadings of the items were greater than their respective maximum cross-factor loadings.

Structural models per group using CB-SEM with equal factor loadings (with restriction) $\times$ different factor loadings (without restriction) are displayed in Tables 24, 25 and 26, and Figures 10 and 9 show the models.

Table 24. Structural model for Group 1 using structural equation modeling based on covariance.

\begin{tabular}{ccccccc}
\hline Endogenous & Exogenous & \multicolumn{5}{c}{ No restriction } \\
\cline { 3 - 7 } & & $\beta$ & SE $\left(\beta^{1}\right)$ & CI $-\mathbf{9 5 \%} \mathbf{2}^{2}$ & $p$-value & $R^{2}$ \\
\hline Quality & Trust & 0,796 & 0,007 & {$[0,782 ; 0,810]$} & $<0,001$ & $49,1 \%$ \\
\hline Value & Quality & $-0,160$ & 0,004 & {$[-0,168 ;-0,152]$} & $<0,001$ & $5,9 \%$ \\
\hline \multirow{2}{*}{ Satisfaction } & Trust & 0,379 & 0,006 & {$[0,367 ; 0,391]$} & $<0,001$ & \\
& Quality & 0,410 & 0,005 & {$[0,40 ; 0,420]$} & $<0,001$ & $79,0 \%$ \\
& Value & 0,004 & 0,004 & {$[-0,004 ; 0,012]$} & 0,303 & \\
\hline Loyalty & Trust & 0,313 & 0,010 & {$[0,293 ; 0,333]$} & $<0,001$ & $17,8 \%$ \\
& Satisfaction & 0,060 & 0,011 & {$[0,038 ; 0,082]$} & $<0,001$ \\
\hline \hline Quality & Trust & 0,793 & 0,006 & {$[0,781 ; 0,805]$} & $<0,001$ & $49,1 \%$ \\
\hline Value & Quality & $-0,169$ & 0,005 & {$[-0,179 ;-0,159]$} & $<0,001$ & $5,9 \%$ \\
\hline \multirow{2}{*}{ Satisfaction } & Trust & 0,376 & 0,006 & {$[0,364 ; 0,388]$} & $<0,001$ & \\
& Quality & 0,408 & 0,005 & {$[0,398 ; 0,418]$} & $<0,001$ & $79,0 \%$ \\
& Value & 0,004 & 0,004 & {$[-0,004 ; 0,012]$} & 0,297 & \\
\hline Loyalty & Trust & 0,303 & 0,010 & {$[0,283 ; 0,323]$} & $<0,001$ & $17,8 \%$ \\
& Satisfaction & 0,058 & 0,011 & {$[0,036 ; 0,080]$} & $<0,001$ & \\
\hline \hline
\end{tabular}

${ }^{1}$ Standard Error; ${ }^{2}$ Bootstrap interval.

Table 25. Structural model for Group 2 using structural equation modeling based on covariance.

\begin{tabular}{ccccccc}
\hline Endogenous & Exogenous & \multicolumn{5}{c}{ No restriction } \\
\cline { 3 - 7 } & & $\beta$ & SE $\left(\beta^{1}\right)$ & CI $-\mathbf{9 5 \%} \mathbf{2}^{2}$ & $p$-value & $R^{2}$ \\
\hline Quality & Trust & 0,817 & 0,006 & {$[0,805 ; 0,829]$} & $<0,001$ & $47,6 \%$ \\
\hline Value & Quality & $-0,176$ & 0,005 & {$[-0,186 ;-0,166]$} & $<0,001$ & $5,1 \%$ \\
\hline \multirow{2}{*}{ Satisfaction } & Trust & 0,395 & 0,006 & {$[0,383 ; 0,407]$} & $<0,001$ & \\
& Quality & 0,392 & 0,005 & {$[0,382 ; 0,402]$} & $<0,001$ & $76,3 \%$ \\
& Value & $-0,001$ & 0,003 & {$[-0,007 ; 0,005]$} & 0,668 & \\
\hline Loyalty & Trust & 0,300 & 0,009 & {$[0,282 ; 0,318]$} & $<0,001$ & $17,6 \%$ \\
& Satisfaction & 0,070 & 0,009 & {$[0,052 ; 0,088]$} & $<0,001$ \\
\hline \hline Quality & Trust & 0,819 & 0,006 & {$[0,807 ; 0,831]$} & $<0,001$ & $47,7 \%$ \\
\hline Value & Quality & $-0,165$ & 0,004 & {$[-0,173 ;-0,157]$} & $<0,001$ & $5,1 \%$ \\
\hline \multirow{2}{*}{ Satisfaction } & Trust & 0,392 & 0,005 & {$[0,382 ; 0,402]$} & $<0,001$ & \\
& Quality & 0,388 & 0,005 & {$[0,378 ; 0,398]$} & $<0,001$ & $76,4 \%$ \\
& Value & $-0,001$ & 0,003 & {$[-0,007 ; 0,005]$} & 0,662 & \\
\hline Loyalty & Trust & 0,308 & 0,009 & {$[0,290 ; 0,326]$} & $<0,001$ & $17,6 \%$ \\
& Satisfaction & 0,072 & 0,009 & {$[0,054 ; 0,09]$} & $<0,001$ & \\
\hline \hline
\end{tabular}

" ${ }^{1}$ Standard Error; ${ }^{2}$ Bootstrap interval.

Table 26. Structural model for Group 3 using structural equation modeling based on covariance.

\begin{tabular}{ccccccc}
\hline \multirow{2}{*}{ Endogenous } & Exogenous & \multicolumn{7}{c}{ No restriction } \\
\cline { 3 - 7 } & & $\beta$ & SE $\left(\beta^{1}\right)$ & CI $-\mathbf{9 5 \%} \mathbf{F}^{2}$ & $p$-value & $R^{2}$ \\
\hline Quality & Trust & 0,812 & 0,007 & {$[0,798 ; 0,826]$} & $<0,001$ & $48,1 \%$ \\
\hline Value & Quality & $-0,162$ & 0,004 & {$[-0,170 ;-0,154]$} & $<0,001$ & $6,0 \%$ \\
\hline \multirow{2}{*}{ Satisfaction } & Trust & 0,382 & 0,006 & {$[0,370 ; 0,394]$} & $<0,001$ & \\
& Quality & 0,385 & 0,005 & {$[0,375 ; 0,395]$} & $<0,001$ & $77,3 \%$ \\
& Value & 0,004 & 0,004 & {$[-0,004 ; 0,012]$} & 0,368 & \\
\hline Loyalty & Trust & 0,280 & 0,009 & {$[0,262 ; 0,298]$} & $<0,001$ & $15,9 \%$ \\
& Satisfaction & 0,049 & 0,010 & {$[0,029 ; 0,069]$} & $<0,001$ \\
\hline \hline Quality & Trust & 0,811 & 0,006 & {$[0,799 ; 0,823]$} & $<0,001$ & $48,1 \%$ \\
\hline Value & Quality & $-0,170$ & 0,004 & {$[-0,178 ;-0,162]$} & $<0,001$ & $6,0 \%$ \\
\hline \multirow{2}{*}{ Satisfaction } & Trust & 0,387 & 0,005 & {$[0,377 ; 0,397]$} & $<0,001$ & \\
& Quality & 0,390 & 0,005 & {$[0,380 ; 0,40]$} & $<0,001$ & $77,3 \%$ \\
\hline Loyalty & Value & 0,003 & 0,004 & {$[-0,005 ; 0,011]$} & 0,358 & \\
& Trust & 0,280 & 0,009 & {$[0,262 ; 0,298]$} & $<0,001$ & $15,9 \%$ \\
& Satisfaction & 0,048 & 0,010 & {$[0,028 ; 0,068]$} & $<0,001$ & \\
\hline \hline
\end{tabular}

${ }^{1}$ Standard Error; ${ }^{2}$ Bootstrap interval. 


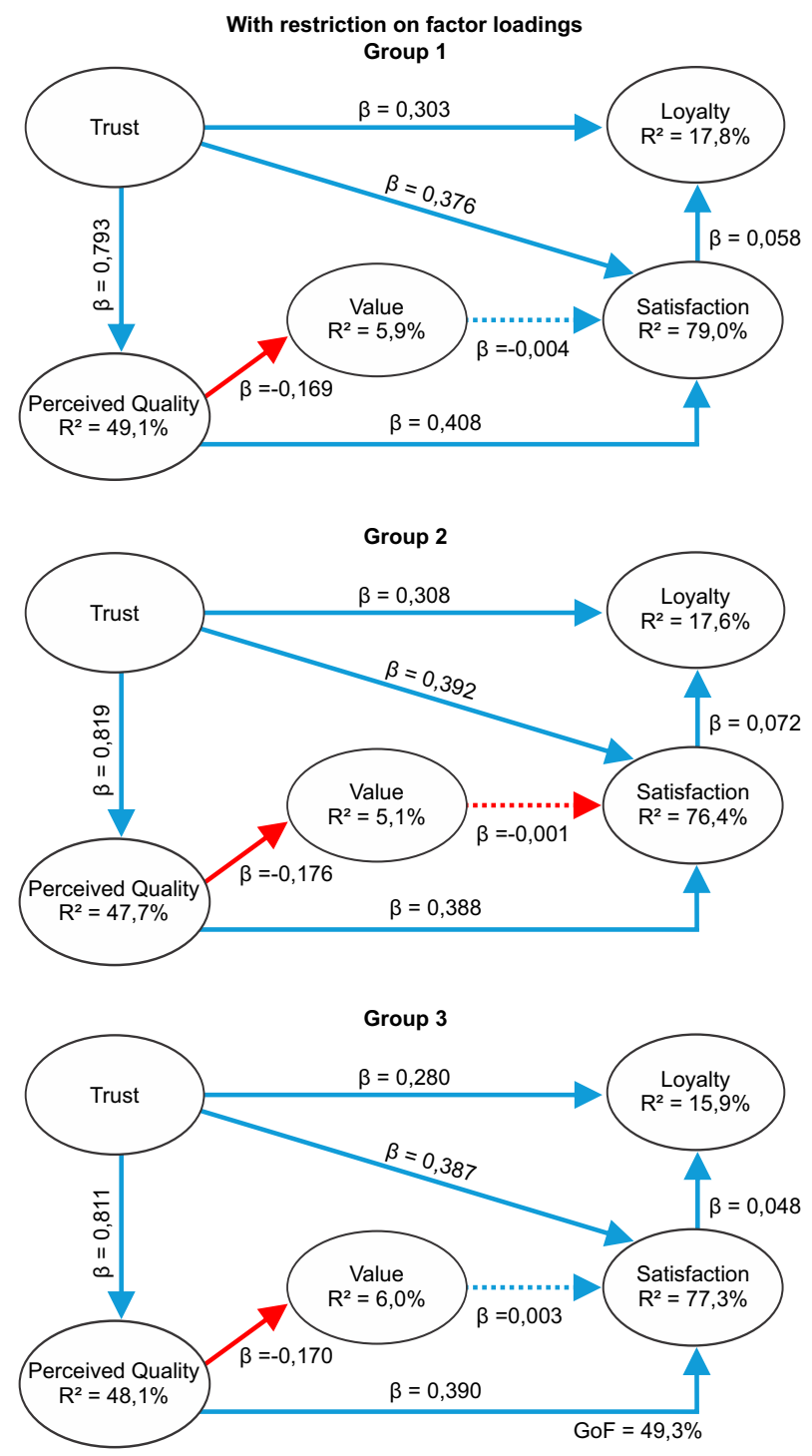

Figure 9. Structural model of with restriction Groups using structural equation modeling based on covariance.

Regarding the quality construct, there was a significant and positive influence of trust for all models with restriction on factorial loadings: Group 1 with $\beta=0.793$, Group 2 with $\beta=0.819$, Group 3 with $\beta=0.811$. There was also a significant and positive influence of trust for all models with no restriction on factor loadings: Group 1 with $\beta=0.796$, Group 2 with $\beta=0.817$, Group 3 with $\beta=0.812$. The $p$-value was $<$ 0.001 for all groups evaluated with and without restriction. Overall, quality variability was best explained by trust in Group 1 with $49.1 \%$. For the value construct, there was a significant and negative influence of quality on all models with restriction on factor loadings: Group 1 with $\beta=-0.169$, Group 2 with $\beta=-0.165$, Group 3 with $\beta=-0.170$ and without restriction on factor loadings: Group 1 with $\beta=-0.160$, Group 2 with $\beta=$ -0.176 , Group 3 with $\beta=-0.162$. A $p$-value $<0.001$ for all groups evaluated with and without restriction. Overall, the variability of the value was better explained by the quality in Group 3 with $6.0 \%$.

Regarding the satisfaction construct, there was a significant and positive influence of trust in all models: with restriction on factor loadings: Group 1 with $\beta=0.376$, Group 2 with $\beta=0.392$, Group 3 with $\beta=0.387$. With restriction on factor loadings: Group 1 with $\beta=0.379$, Group 2 with $\beta=0.395$, Group 3 with $\beta=0.382$. In the quality construct, there was a significant and positive influence on satisfaction for all 


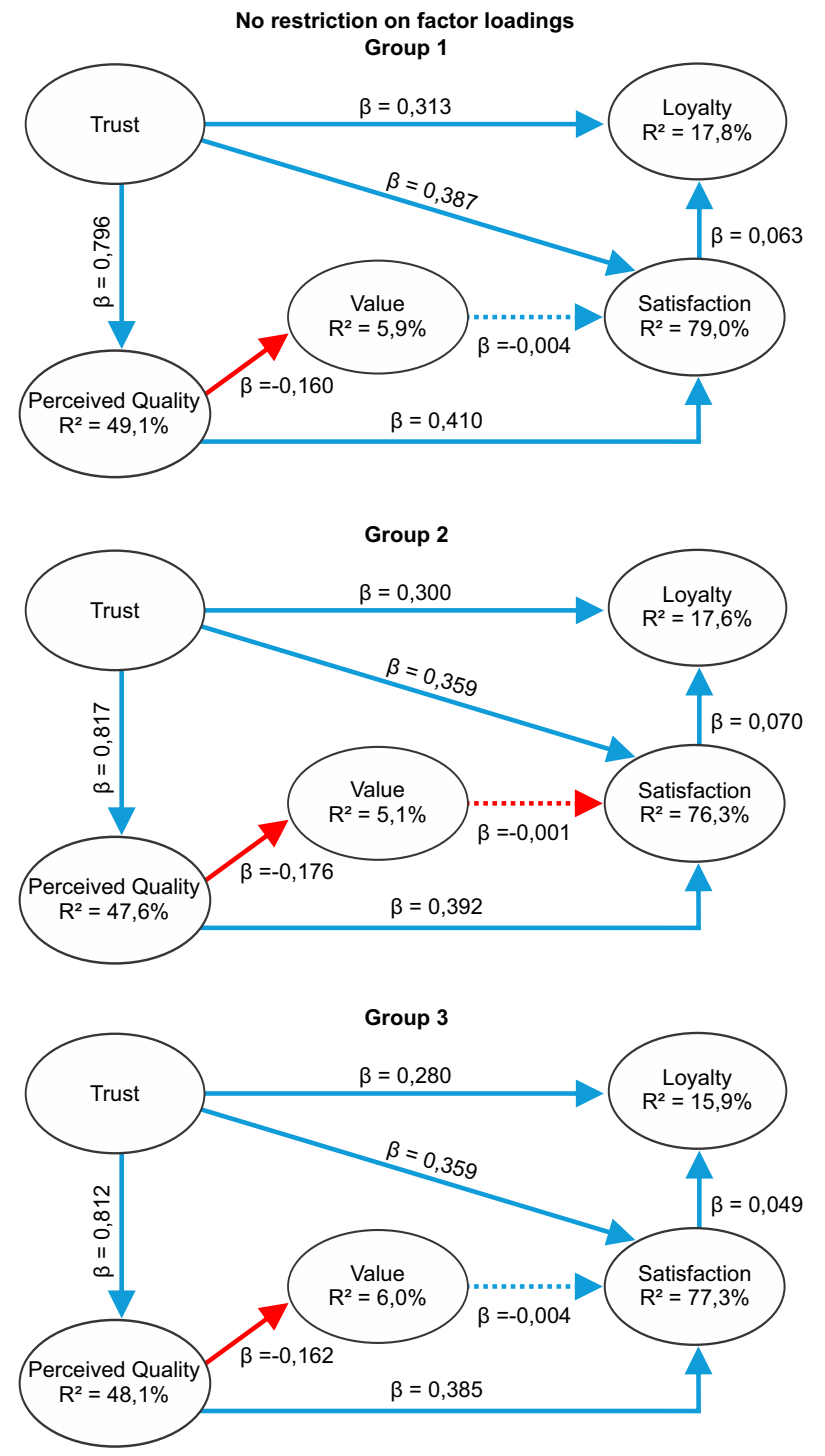

Figure 10. Structural model of no restriction Groups using structural equation modeling based on covariance.

models with restriction on factor loadings: Group 1 with $\beta=0.408$, Group 2 with $\beta=0.388$, Group 3 with $\beta=0.390$ and no restriction on factor loadings: Group 1 with $\beta=0.410$, Group 2 with $\beta=0.392$, Group 3 with $\beta=0.385$. The variability in satisfaction was best explained by trust, quality, and value in Group 1 with $79.0 \%$.

Regarding the loyalty construct, there was a significant and positive influence of trust in all models: with restriction on factor loadings: Group 1 with $\beta=0.303$, Group 2 with $\beta=0.308$, Group 3 with $\beta=0.280$, and no restriction on factor loadings: Group 1 with $\beta=0.313$, Group 2 with $\beta=0.300$, Group 3 with $\beta=0.280$. There was a significant and positive influence of satisfaction on loyalty among all models with restriction on factor loadings: Group 1 with $\beta=0.058$, Group 2 with $\beta=0.072$, Group 3 with $\beta=$ 0.048 , and without restriction on factor loadings: Group 1 with $\beta=0.060$, Group 2 with $\beta=0.070$, Group 3 with $\beta=0.049$. Overall, the variability of loyalty was best explained by trust and satisfaction in Group 1 with $17.8 \%$.

The results for the three groups were similar between the models with and without restriction in factor loadings. The adjustments with total restriction of equality in the factor loading and later with the total restriction of equality in the factor loadings and intercepts are shown in Table 27. Thus enabling, based on the difference in the $\chi^{2}$ statistic and the degrees of freedom of the nested models, to test the metric and scalar equivalence 
through cluster analysis. Metric non-equivalence implies that depending on the group, the way of interpreting and using the scale is different, while scalar non-equivalence implies that the importance attributed to the constructs varies from group to group; that is, there are differences between groups in how to quantify the constructs.

Table 27. Analysis of metric and scalar equivalence.

\begin{tabular}{ccccccc}
\hline Restriction & $\chi^{2}$ & DF & CFI & TLI & RMSEA & $p$-value \\
\hline- & 175750,800 & 1374,000 & 0,932 & 0,926 & 0,054 & - \\
\hline Factor Loads & 176331,700 & 1428,000 & 0,931 & 0,928 & 0,053 & $<0,001$ \\
Factor Loads + Intercepts & 177771,000 & 1482,000 & 0,929 & 0,929 & 0,053 & $<0,001$ \\
\hline \hline
\end{tabular}

From the results shown in Table 27, it can be observed that there was no metric or scalar equivalence between the groups because $p$-value $\leq 0,001$, and $\mathrm{RMSEA}<0,05$. Thus, the interpretation of the scales was different between the groups and the importance attributed to the constructs varied from group to group. The quality measures of the adjustments did not vary even with the restrictions of the factor loadings and intercepts; that is, the models presented similar adjustments. Table 28 shows the quality measures of the fit of the models by group with and without restriction using structural equation modeling based on covariance.

Table 28. Metric and scalar equivalence for groups.

\begin{tabular}{ccccc}
\hline Mode & CFI & TLI & RMSEA & $p$-value \\
\hline No restriction (Yearly) & 0,932 & 0,926 & 0,054 & 0,000 \\
With restriction (Yearly) & 0,931 & 0,928 & 0,053 & 0,000 \\
Group 1 & 0,926 & 0,920 & 0,056 & 0,000 \\
Group 2 & 0,943 & 0,938 & 0,050 & 0,000 \\
Group 3 & 0,924 & 0,917 & 0,056 & 0,000 \\
\hline \hline
\end{tabular}

From Table 28, all models had CFI $>0,8$, TLI $>0,8$, RMSEA $<0,1$ and $p$-value $<$ 0,05 , the latter being significant (the indicated values are reference values). Thus, all models had satisfactory adjustments and, even demonstrated in Tables 27 and 28, that the factor loadings are different between the groups, and the model with the same factor loadings showed adjustment as much as the model with the different factor loadings.

\subsection{Comparison Between Structural Equation Modeling Based on Partial Least Squares and Based on Covariance}

There are several methods for estimating convergent validity, including factorial load evaluation. The high factorial load indicates that they converge to a common point, that is, there is convergent validity. The literature indicates that the factorial load can be $\leq 0,5$ but the ideal is to be $>0,5$. If a given item displays a value $<0,5$, it becomes a strong candidates to leave the factorial model. From Tables 8 and 11, all item values have factorial load $>0,5$, not needing to exclude any item for structural equation modeling based on partial least squares (PLS-SEM) and for structural equation modeling based on covariance (CB-SEM). The comparative analyses of convergent validity, discriminant validity, and reliability of the constructs for the measurement models of the PLS-SEM and CB-SEM are shown in Tables 29 and 30.

According to Fornell's criterio [39], when evaluating the PLS-SEM and CB-SEM methods, there is discriminant validation in all constructs, except the satisfaction construct, given that the maximum shared variances (MSV) are lower than the respective AVE. Using the cross-factor loading method [44], the satisfaction construct reaches the discriminant validation criterion, as the factorial load of the items is higher than their respective maximum cross-factor loadings. In addition, from the comparison between the AVE of the constructs by applying PLS-SEM and CB-SEM, Table 29 shows that the PLS-SEM obtained better results than the CB-SEM, considering that its constructs trust, value, satisfaction, and loyalty achieved superior values. As the average variance extracted (AVE) is an indicator associated with the quality of the measure, the application of the structural model from the PLS-SEM generates results that are more consistent. 
Table 29. Comparison of measurement models.

\begin{tabular}{|c|c|c|c|c|}
\hline & Construct & $\mathbf{C R}^{1}$ & $\mathbf{A V E}^{2}$ & $\mathbf{M S V}^{3}$ \\
\hline \multirow{5}{*}{ PLS-SEM } & Trust & 0,947 & 0,816 & 0,579 \\
\hline & Quality & 1,000 & 1,000 & 0,659 \\
\hline & Value & 0,943 & 0,806 & 0,176 \\
\hline & Satisfaction & 0,964 & 0,585 & 0,659 \\
\hline & Loyalty & 0,934 & 0,776 & 0,176 \\
\hline \multirow{5}{*}{ CB-SEM } & Trust & 0,925 & 0,755 & 0,681 \\
\hline & Quality & 1,000 & 1,000 & 0,694 \\
\hline & Value & 0,921 & 0,740 & 0,034 \\
\hline & Satisfaction & 0,961 & 0,561 & 0,694 \\
\hline & Loyalty & 0,910 & 0,704 & 0,187 \\
\hline
\end{tabular}

Table 30. Comparison of measurement models through factorial loads.

\begin{tabular}{lccc}
\hline & Construct & Mean FL $^{1}$ & Mean Max (FLC.) $^{2}$ \\
\hline & Trust & 0,903 & 0,687 \\
PLS-SEM & Quality & 1,000 & 0,812 \\
& Value & 0,897 & 0,377 \\
& Satisfaction & 0,764 & 0,622 \\
& Loyalty & 0,880 & 0,402 \\
\hline \multirow{2}{*}{ CB-SEM } & Trust & 0,869 & 0,693 \\
& Quality & 1,000 & 0,829 \\
& Value & 0,861 & 0,351 \\
& Satisfaction & 0,749 & 0,638 \\
\hline \hline & Loyalty & 0,839 & 0,403 \\
\hline
\end{tabular}

From the comparison between the averages of the factorial load of the constructs in the application of the PLS-SEM and the CB-SEM, it is also possible to observe in Table 30 that the PLS-SEM obtained better results than the CB-SEM, since its constructs trust, value, satisfaction, and loyalty achieved superior values. Factorial load indicates the amount of a given factor explains a given variable, the application of the structural model based on PLS-SEM generates better results. Another measure is the AVE, which checks the proportion of variance of items by the construct to which they belong. Thus, as in the evaluation of factorial load, when AVE $\geq 0,4$, the model is considered valid. Therefore, in Table 29 there is convergent validation in all constructs, whether using PLS-SEM or CB-SEM, as they all have AVE $\geq 0,4$.

To confirm the convergent validity, the composite reliability is usually evaluated, which is the assessment of the adequate internal consistency for the PLS-SEM as it prioritizes the variables according to their reliability. As shown in Table 29, the constructs had CR $\geq 0,90$, for both PLS-SEM and CB-SEM, with the required levels being CR $\geq 0,60$. From the comparison between the CR of the constructs by applying the PLS-SEM and CB-SEM, it is also possible to observe in Table 29 that PLS-SEM obtained better results than CB-SEM.

When comparing the construct's composite reliability (CR) by applying PLS-SEM and CB-SEM, we observed that the trust, value, satisfaction, and loyalty constructs of the PLS-SEM reached better values. As composite reliability (CR) is an indicator associated with the quality of the measure, the application of the structural model based on PLS-SEM generates better results. In Tables 29 and 30, construct quality for having a single indicator is: i) $\mathrm{CR}=1$, ii) $\mathrm{AVE}=1$, and iii) factor loading $=1$ for both structural equation models. The comparative results of the general structural model are listed in Table 31.

Table 31. Comparison of structural models.

\begin{tabular}{cccc|cc}
\hline \multirow{2}{*}{ Endogenous } & Exogenous & \multicolumn{2}{c|}{$\beta$} & \multicolumn{2}{c}{$R^{2}$} \\
\cline { 3 - 6 } & & PLS-SEM & CB-SEM & PLS-SEM & CB-SEM \\
\hline Quality & Trust & 0,672 & 0,811 & $45,2 \%$ & $48,8 \%$ \\
\hline Value & Quality & $-0,238$ & $-0,175$ & $5,7 \%$ & $6,0 \%$ \\
\hline \multirow{2}{*}{ Satisfaction } & Trust & 0,391 & 0,387 & \multirow{2}{*}{$74,4 \%$} & $77,7 \%$ \\
& Quality & 0,548 & 0,393 & & \\
& Value & $-0,007$ & 0,001 & & $18,2 \%$ \\
& Trust & 0,346 & 0,308 & $21,8 \%$ & \\
& Satisfaction & 0,146 & 0,063 & & \\
\hline \hline
\end{tabular}


The trust construct has a greater influence on the quality construct and presents a higher $R^{2}$ in CB-SEM than in PLS-SEM. In CB-SEM, the value construct exerts a greater influence on the quality construct and presented a higher $R^{2}$ in the PLS-SEM. On the other hand, in PLS-SEM, there is a greater influence of the trust, quality, and value constructs on the satisfaction construct than in CB-SEM, but in CB-SEM the quality of the model's fit is better because of the higher $R^{2}$ compared to PLS-SEM. Finally, the trust construct and the satisfaction construct exert greater influence on the loyalty construct and present a higher $R^{2}$ in PLS-SEM than in CB-SEM. Comparative analyses of convergent validity, discriminant validity, and reliability of the constructs in the measurement models of the groups are shown in Tables 32 and 33.

Table 32. Comparison of group measurement models.

\begin{tabular}{|c|c|c|c|c|}
\hline & Construct & $\mathbf{C R}^{1}$ & $\mathrm{AVE}^{2}$ & $\mathrm{MSV}^{3}$ \\
\hline & Trust & 0,948 & 0,822 & 0,587 \\
\hline Group 1 & Quality & 1,000 & 1,000 & 0,676 \\
\hline \multirow{3}{*}{ PLS-SEM } & Value & 0,939 & 0,793 & 0,056 \\
\hline & Satisfaction & 0,965 & 0,591 & 0,676 \\
\hline & Loyalty & 0,933 & 0,773 & 0,206 \\
\hline & Trust & 0,948 & 0,819 & 0,569 \\
\hline Group 2 & Quality & 1,000 & 1,000 & 0,646 \\
\hline \multirow[t]{3}{*}{ PLS-SEM } & Value & 0,951 & 0,830 & 0,048 \\
\hline & Satisfaction & 0,965 & 0,593 & 0,646 \\
\hline & Loyalty & 0,937 & 0,785 & 0,203 \\
\hline & Trust & 0,942 & 0,803 & 0,567 \\
\hline Group 3 & Quality & 1,000 & 1,000 & 0,651 \\
\hline \multirow{3}{*}{ PLS-SEM } & Value & 0,935 & 0,783 & 0,056 \\
\hline & Satisfaction & 0,961 & 0,565 & 0,651 \\
\hline & Loyalty & 0,928 & 0,756 & 0,191 \\
\hline & Trust & $\overline{0,926}$ & 0,758 & 0,679 \\
\hline Group 1 & Quality & 1,000 & 1,000 & 0,697 \\
\hline \multirow[t]{3}{*}{ CB-SEM } & Value & 0,932 & 0,773 & 0,043 \\
\hline & Satisfaction & 0,962 & 0,569 & 0,697 \\
\hline & Loyalty & 0,915 & 0,715 & 0,184 \\
\hline & Trust & 0,926 & 0,758 & 0,668 \\
\hline Group 2 & Quality & 1,000 & 1,000 & 0,659 \\
\hline \multirow[t]{3}{*}{ CB-SEM } & Value & 0,932 & 0,773 & 0,032 \\
\hline & Satisfaction & 0,962 & 0,569 & 0,668 \\
\hline & Loyalty & 0,915 & 0,715 & 0,177 \\
\hline & Trust & 0,918 & 0,737 & 0,680 \\
\hline Group 3 & Quality & 1,000 & 1,000 & 0,687 \\
\hline \multirow[t]{3}{*}{ CB-SEM } & Value & 0,909 & 0,709 & 0,046 \\
\hline & Satisfaction & 0,957 & 0,540 & 0,687 \\
\hline & Loyalty & 0,900 & 0,680 & 0,166 \\
\hline
\end{tabular}

In Table 32, there is convergent validation in all constructs, whether using PLS-SEM or CB-SEM for all groups (Group 1, Group 2, Group 3), since all have AVE $\geq 0,40$. According to Fornell's criterion [39], when evaluating the PLS-SEM and CB-SEM methods show discriminant validity in all constructs, except the satisfaction construct, given that MSV < AVE. From the comparison between the averages of the factor loadings of the constructs by applying PLS-SEM and CB-SEM, it is possible to observe in Table 33 that the PLS-SEM obtained better results than the CB-SEM in all groups. This occurred because the constructs achieved better values for PLS-SEM than CB-SEM.

Using the method of cross-factor loadings [44], the satisfaction construct reached the discriminant validation criterion because the factor loadings of the items were higher than their respective maximum cross-factor loadings in all groups. In addition, based on the comparison between the AVEs of the constructs by applying PLS-SEM and CB-SEM, it can be observed in Table 32 that the PLS-SEM obtained better results than the CB-SEM for all groups. From Table 32, it is observed that the index $\mathrm{CR} \geq 0,90$ for constructs using PLS-SEM or CB-SEM in all groups. From the comparison between the CR of the constructs by applying PLS-SEM and CB-SEM, it can be observed in Table 32 that the PLS-SEM obtained better results than the CB-SEM in all groups. The quality construct for having a single indicator presents values of CR, factor loading and AVE equal to 1 in all cases. The 
Table 33. Comparison of measurement models of groups using the factor loadings.

\begin{tabular}{|c|c|c|c|}
\hline & Construct & Mean $\mathbf{F L}^{1}$ & Mean Max (SFL) ${ }^{2}$ \\
\hline & Trust & 0,907 & 0,695 \\
\hline Group 1 & Quality & 1,000 & 0,822 \\
\hline \multirow{3}{*}{ PLS-SEM } & Value & 0,890 & 0,367 \\
\hline & Satisfaction & 0,768 & 0,632 \\
\hline & Loyalty & 0,879 & 0,399 \\
\hline & Trust & 0,905 & 0,683 \\
\hline Group 2 & Quality & 1,000 & 0,804 \\
\hline \multirow[t]{3}{*}{ PLS-SEM } & Value & 0,911 & 0,387 \\
\hline & Satisfaction & 0,769 & 0,620 \\
\hline & Loyalty & 0,885 & 0,400 \\
\hline & Trust & 0,896 & 0,675 \\
\hline Group 3 & Quality & 1,000 & 0,807 \\
\hline \multirow{3}{*}{ PLS-SEM } & Value & 0,884 & 0,345 \\
\hline & Satisfaction & 0,751 & 0,607 \\
\hline & Loyalty & 0,869 & 0,375 \\
\hline & Trust & 0,873 & 0,70 \\
\hline Group 1 & Quality & 1,000 & 0,835 \\
\hline \multirow[t]{3}{*}{ CB-SEM } & Value & 0,850 & 0,344 \\
\hline & Satisfaction & 0,797 & 0,638 \\
\hline & Loyalty & 0,839 & 0,403 \\
\hline & Trust & 0,871 & 0,687 \\
\hline Group 2 & Quality & 1,000 & 0,822 \\
\hline \multirow[t]{3}{*}{ CB-SEM } & Value & 0,879 & 0,361 \\
\hline & Satisfaction & 0,755 & 0,632 \\
\hline & Loyalty & 0,846 & 0,401 \\
\hline & Trust & 0,858 & 0,683 \\
\hline Group 3 & Quality & 1,000 & 0,827 \\
\hline \multirow[t]{3}{*}{ CB-SEM } & Value & 0,842 & 0,318 \\
\hline & Satisfaction & 0,735 & 0,619 \\
\hline & Loyalty & 0,825 & 0,374 \\
\hline
\end{tabular}

comparative results of the general structural model for all groups are shown in Tables 34, 35 , and 36 .

Table 34. Comparison of the Group 1 structural model.

\begin{tabular}{cccc|cc}
\hline Endogenous & Exogenous & \multicolumn{2}{c|}{$\beta$} & \multicolumn{2}{c}{$R^{2}$} \\
\cline { 3 - 6 } & & PLS-SEM & CB-SEM & PLS-SEM & CB-SEM \\
\hline Quality & Trust & 0,675 & 0,796 & $45,5 \%$ & $49,1 \%$ \\
\hline Value & Quality & $-0,236$ & $-0,16$ & $5,6 \%$ & $5,9 \%$ \\
\hline \multirow{2}{*}{ Satisfaction } & Trust & 0,388 & 0,379 & \multirow{2}{*}{$75,8 \%$} & $79,0 \%$ \\
& Quality & 0,559 & 0,41 & & \\
\hline \multirow{2}{*}{ Loyalty } & Value & $-0,004$ & 0,004 & & \\
& Trust & 0,345 & 0,313 & $21,5 \%$ & \\
& Satisfaction & 0,143 & 0,06 & & \\
\hline \hline
\end{tabular}

Table 35. Comparison of the Group 2 structural model.

\begin{tabular}{cccc|cc}
\hline \multirow{2}{*}{ Endogenous } & \multirow{2}{*}{ Exogenous } & \multicolumn{2}{c|}{$\beta$} & \multicolumn{2}{c}{$R^{2}$} \\
\cline { 3 - 6 } & & PLS-SEM & CB-SEM & PLS-SEM & CB-SEM \\
\hline Quality & Trust & 0,665 & 0,817 & $44,3 \%$ & $47,6 \%$ \\
\hline Value & Quality & $-0,22$ & $-0,176$ & $4,8 \%$ & $5,1 \%$ \\
\hline \multirow{2}{*}{ Satisfaction } & Trust & 0,391 & 0,395 & \multirow{2}{*}{$76,3 \%$} \\
& Quality & 0,542 & 0,392 & $73,3 \%$ & \\
& Value & $-0,011$ & $-0,001$ & & \multirow{2}{*}{$17,6 \%$} \\
\hline Loyalty & Trust & 0,341 & 0,3 & $21,2 \%$ & \\
& Satisfaction & 0,145 & 0,07 & & \\
\hline \hline
\end{tabular}

Table 36. Comparison of the Group 3 structural model.

\begin{tabular}{cccc|cc}
\hline \multirow{2}{*}{ Endogenous } & Exogenous & \multicolumn{2}{c|}{$\beta$} & \multicolumn{2}{c}{$R^{2}$} \\
\cline { 3 - 6 } & & PLS-SEM & CB-SEM & PLS-SEM & CB-SEM \\
\hline Quality & Trust & 0,665 & 0,812 & $44,2 \%$ & $48,1 \%$ \\
\hline Value & Quality & $-0,236$ & $-0,162$ & $5,6 \%$ & $6,0 \%$ \\
\hline \multirow{2}{*}{ Satisfaction } & Trust & 0,387 & 0,382 & \multirow{2}{*}{$73,6 \%$} & $77,3 \%$ \\
& Quality & 0,549 & 0,385 & & \\
\hline Loyalty & Value & $-0,004$ & 0,004 & & \\
& Trust & 0,33 & 0,28 & $20,0 \%$ & \\
& Satisfaction & 0,141 & 0,049 & & \\
\hline \hline
\end{tabular}


The trust construct exerts a greater influence on the quality construct and presents a higher $R^{2}$ in the CB-SEM than in the PLS-SEM for all the groups. The value construct exerts a greater influence on the quality construct in PLS-SEM than in CB-SEM; however, CB-SEM presents a higher $R^{2}$ than PLS-SEM for all groups. In PLS-SEM, there is almost always greater influence of the trust, quality, and value constructs on the satisfaction construct than in CB-SEM, but in CB-SEM, the quality of the model fit is better because of the higher $R^{2}$ when compared to PLS-SEM in all groups. Finally, the trust construct and satisfaction construct exerted a greater influence on the loyalty construct and presented a higher $R^{2}$ in PLS-SEM than in CB-SEM for all groups.

\subsection{Discussion}

Several studies measure consumer satisfaction in different segments of basic services, but studies on electricity concessionaires are incipient. To ensure survival and profitability in a competitive scenario, electricity concessionaires must develop tools capable of measuring and supporting the management of the quality of services provided, perceived quality, and behavioral intentions of consumers. Therefore, this study sought to consider the potential arising from the comparison of structural equation modeling by partial least squares (PLSSEM) and based on covariance (CB-SEM). To verify the quality of the PLS-SEM and CB-SEM structural equation modeling adjustments, indices and metrics were used, such as average variance extracted AVE, composite reliability $\mathrm{CR}$, coefficient of determination $R^{2}$, and quality of fit GoF. In the CB-SEM approach, specific parameters are also used to assess the quality of the model, such as comparative fit index (CFI), Tucker-Lewis index (TLI) and root mean square error of approximation (RMSEA), in addition to the $p$-value to verify if the RMSEA is statistically within the desired.

For PLS-SEM, the trust construct explains $45.2 \%$ of the variability in the quality construct, and if the residential consumers of electric energy perceive that the electric energy concessionaire or licensee is trustworthy and provides true information; consequently the quality perceived by the provision of services tends to be higher. In addition, in PLS-SEM, the quality construct explains $5.7 \%$ of the variability of the value construct, so if the services provided have quality concerning customer expectations, then the amount paid will tend to be considered fair. In the trust construct on the satisfaction construct, it is measured that if the residential electric energy consumers perceive that the electric energy concessionaire or licensee is trustworthy and provides true information; he will be more satisfied. The influence measured between the quality construct on the satisfaction construct defines that if the services provided have a quality assessment in relation to customer expectations, there will be a tendency for the customer to be satisfied. There is also the influence of the value construct on the satisfaction construct, defining that the higher the amount paid in energy bills, the lower the customer satisfaction. The trust, quality, and value constructs can explain $74.4 \%$ of the variability of the satisfaction construct, and thetrust and satisfaction constructs explained $21.8 \%$ of the variability of the loyalty construct.

The IASC honors, for the most part, the best rated distributors only based on the opinion of urban residential consumers. The analysis performed by the IASC needs to be improved to obtain the perceptions of all categories of consumers. The numbers measured in this work are important to map and monitor the concessionaires, but the perception expressed by consumers is the important in the evaluation of electricity distribution services, contributing to the improvement of these services. Consumers expect electricity distributors to improve and become increasingly suited to economic and financial reality, delivering quality in the electricity supplied.

For the CB-SEM, regarding quality, there was an influence of the trust construct, and the greater the trust, the greater the quality, since the trust construct was able to explain $48.8 \%$ of the quality variability. The value construct is influenced by the inverse of the quality construct, and the higher the quality perceived by the customer, the more he will feel that the amount paid is high. Quality explained 6.0\% of the variability in the 
value. Regarding satisfaction, there was an influence on the trust construct, with the greater the trust, the greater the satisfaction. There was also an influence of quality on satisfaction, so that the higher the quality, the greater the satisfaction. Finally, there was no significant difference of the value on satisfaction. The trust, quality, and value constructs together explained $77.7 \%$ of the variability in satisfaction, trust, and satisfaction, explaining $18.2 \%$ of the variability in loyalty.

For the choice of which model to apply, from the perspective of the coefficients of determination $R^{2}$, the CB-SEM would have better quality in the model adjustments because $R^{2}$ of its relations is higher when compared to $R^{2}$ of the PLS-SEM relations. This indicates that the independent constructs of CB-SEM better explain the dependent constructs. However, if the average variance extracted AVE is used, for example, PLS-SEM can be chosen as the model that produces better measurement quality. The results of PLS-SEM and CB-SEM in this study are closely related, with small differences in the quality of the measurement model. Both approaches return, analyzing only the adjustment inputs and the same results. As a result, it is not possible to say that one method is better than another. However, to correctly apply PLS-SEM and CB-SEM, users must understand the purposes for which each approach was developed and applied to generate satisfactory results.

In this research, the ANEEL Consumer Satisfaction Index (IASC) was used to assess residential consumer satisfaction with services provided by electricity distributors, a model derived from the American Customer Satisfaction Index (ACSI) model of satisfaction. The measures used in structural equation modeling (SEM) were developed from a solid theoretical framework by analyzing the psychometric characteristics of the measurements. The PLS-SEM and CB-SEM methodologies tend to be complementary in the sense that the advantages of the non-parametric and variance-based approach can be the disadvantages of the parametric and covariance-based approach and vice versa. New research is being carried out to develop a global measure of adequacy for PLS-SEM. This type of model evaluation criterion is a fundamental requirement for testing and comparing alternative theories with their associated models. Furthermore, future research may contemplate different approaches for response-based clustering, such as FIMIX-PLS, PLS genetic algorithm segmentation, and PLS response-based unit segmentation (REBUS-PLS).

SEM has a confirmatory character, which is not an appropriate technique to explore the relationships between variables. This can be accomplished using other multivariate statistical techniques. Because of this characteristic, the theoretical formulation of hypothetical models is important in the context of SEM because the relationship that must be established between the variables must be based on theoretical assumptions and previous empirical evidence. This function is essential for obtaining theoretically consistent results and models adjusted according to the data. If there is no such evidence in the field of investigation, it is recommended that researchers use other multivariate data analysis techniques that do not have verification characteristics to start the research.

One of the limitations of SEM is that it is part of the multivariate technology family that belongs to the general linear model, in which it is neither sufficient nor possible to evaluate the relationship between variables that do not have a linear relationship pattern. Another limitation of the use of SEM is the size of the samples that must be used, as SEM estimators require considerable variability to carry out the estimation process. The results of this research serve as indicators for decision-making by managers of electricity concessionaires and license holders who must be concerned with the satisfaction of their consumers through the provision of high-quality services. Satisfaction ratings allow for a consistent assessment of service performance over a given period.

It is worth noting that through the analysis of the PLS-SEM in Table 12 and Figure 4 it is observed that $\beta=-0,238$ of the quality construct over the value construct. Similarly, using CB-SEM, Table 13 and Figure 5 show that the value construct was influenced by the quality construct, raising $\beta=-0,175$. This is due to the characteristics of the electricity sector in Brazil. Users of this service do not have another energy supply option and do not yet have sufficient capacity to bargain with their suppliers. In most cases, the improvement 
in service quality does not correspond to a fuller perception of the value perceived by the user, since there is a monopoly. Factors that directly affect rates, such as increases, reductions, discounts, and installments, should have a greater impact on perceived value than on changes in service quality. This fact also explains the expected characteristics associated with the continued consumption of services. In these circumstances, the expectations generated have a normative character; that is, the service standards are the references for users to evaluate them. At the same time, they have a low capacity to negotiate with energy suppliers, which means that, regardless of the level of quality provided, they cannot change their electricity costs. Therefore, the relative weights between quality and value result in low values.

Favorable conjunctures, such as the increase in purchasing power of the population have a positive impact on the residential consumption of households, permanently modifying their spending on electricity and end up generating favorable perception of the distributor's value construct. From another perspective, it should be considered that financial crises tend to devalue the currency of a given country and pressure inflation. As wages do not compensate in real time for the fall in purchasing power, the adjustments of energy tariffs charged assume greater weight in the family budget generating negative perception about the service provided by distributors.

Traditionally, economic theory assumes that individuals consider all possible costs and benefits when making decisions. Based on this statement, consumers act rationally from the perspective of self-interest. This method is useful, but ignores the psychological and social impact of human behavior. In other words, consumers are malleable and emotional individuals whose behavior can be influenced, for example: by local social indications and norms. Interventions can encourage changes in consumer behaviour. In the electricity sector, these interventions can trigger more sustainable behaviors in society to improve energy efficiency and increase the use of renewable energy.

\section{Conclusions}

This study presented as its general objective the application of structural equation modeling by partial least squares (PLS-SEM) and structural equation modeling based on covariance (CB-SEM) to assess the satisfaction of residential electricity consumers about utilities and licensees that provide the services. For this, the specific objectives included conducting an exploratory and descriptive analyses of the data from the Consumer Satisfaction Index. The objectives of the study were achieved, as the comparative analyzes of convergent validity, discriminant validity, and reliability of the constructs for the measurement models demonstrated that PLS-SEM and CB-SEM are complementary and not concurrent so that a method cannot be considered superior to the other.

The weights relative to the quality and value constructs resulted in low $\beta$ values. This is because users have little bargaining power with their energy suppliers, which means that regardless of the level of product quality they deliver, residential consumers cannot change their electricity costs. On the other hand, the application of PLS-SEM and CB-SEM results in higher $\beta$ values between the trust and quality constructs, which highlights the high impact of users' trust in the quality of the service. Therefore, investments in the improvement of distribution systems, service systems, access to the concessionaire/licensee, and information to users lead to greater trust. Therefore, companies must seek to improve the quality of their services so that consumeres remain secure about the offer of these activities.

This study used data from a consumer satisfaction survey questionnaire in all the Brazilian regions. In this way, this research brings the general panorama about the services rendered by the analyzed concessionaires/licensees, as the result of the structural equation models, the average of the countless companies evaluated. Thus, the results of this work can be used to monitor and analyze consumer satisfaction, observe the evolution of the quality of services provided and assist in the development of tools to support decision-making at concessionaires. Residential electricity users can also use this study to better understand the aspects that need improvement on the part of these service providers, based on which 
demand from the competent supervisory body fulfills the proper electricity distribution procedures.

Therefore, we concluded that the significant portion of the variability incident on customer satisfaction can be explained by the trust, quality, and value constructs, with 74.4\% when applying PLS-SEM and 77.7\% when applying CB-SEM. This indicates that user satisfaction can be achieved if the electricity concessionaires/licensees demonstrate concern for the interests of the customer/user, including providing correct and true information at the times when requested. Another factor that can lead to user satisfaction is the perceived quality, represented by i) product quality that is related to constant voltage compliance and non-disturbed waveform, ii) quality of service that is related to the continuity of its provision and iii) quality of customer service. Currently, there is a natural monopoly on the electricity distribution service and although consumers are dissatisfied with the amount paid for their bills, they cannot turn to another company and end up not exercising their right to choose.

This study proposes the model of evaluating consumer satisfaction for the electricity sector. In it there is the insertion of the structure that meets the services provided by electricity distributors. The results obtained show that the model has validity and internal consistency, because the results obtained by PLS-SEM and CB-SEM are similar. The proposal presents a flexible model to measure the satisfaction of residential customers in the context of different concessionaires/licensees. Similarly, the model allows concessionaires/licensees to maintain the database on the evolution of these indicators measured using the proposed methodology, as well as to evaluate the evolution of consumer satisfaction in the face of suggestions for improvement strategies. With this, the association model can be established for each distributor indicating the diagnosis of problems and their possible solutions.

Author Contributions: The research and scientific dissemination work was carried out by all authors. Some specific parts had more contributions from one or more authors depending on the author's field. For example: data collection was performed by ASSN and WPC, the data processing part was performed by ASSN, MRCR, APC, JCVS and WPC. The application of the methodology was performed in parts that depended on the method used, in general, all authors performed this part. The writing of the article was performed by ASSN, MRCR and WPC, while the translation into English was performed by the authors APC and JCVS.

Funding: This research was not funded by any institution.

Acknowledgments: The authors would like to thank the Brazilian Electricity Regulatory Agency (ANEEL) for the assistance and reception of the ANEEL Customer Satisfaction Index (IASC) data that supports the reported results. They thank the Foundation for Research Support of the State of Goiás (FAPEG) for the scholarship no 27868 provided and the Federal Institute of Goias (IFG) for making the Computer Laboratory available.

Conflicts of Interest: The authors declare no conflict of interest.

\section{References}

1. P. Kotler, K. K. Lane, Marketing Management, Prentice Hall, 2011.

2. D. R. Boente, P. R. B. Lustosa, Efficiency of electricity distribution companies, RAUSP Management Journal, vol. 55, no. 2, pp. 177-193, 2020.

3. Md. U. H. Uzir, H. Al Halbusi, R. Thurasamy, R. L. T. Hock, M. A. Aljaberi, N. Hasan, M. Hamid, The effects of service quality, perceived value and trust in home delivery service personnel on customer satisfaction: Evidence from a developing country, Journal of Retailing and Consumer Services, vol. 63, 2021.

4. A. O. Pereira, J. B. Soares, R. G. Oliveira, R. P. Queiroz, Energy in Brazil: Toward sustainable development?, Energy Policy, vol. 36, no. 1, pp. 73-83, 2008.

5. V. A. Zeithaml, L. L. Berry, A. Parasuraman, A. "The behavioral consequences of service quality," Journal of Marketing, vol.60, no. 2, pp. 31-46, 1996.

6. Md. U. H. Uzir, I. Jerin, H. Al Halbusi, A. B. A. Hamid, A. S. A. Latiff, " Does quality stimulate customer satisfaction where perceived value mediates and the usage of social media moderates?," Heliyon, vol. 6, no. 12, pp. 1-19, 2020. 
7. Aušra Pažèraitè, Viktorija Bobinaitè, Arvydas Galinis, Vidas Lekavičius, "Combined effects of energy sector development: Assessing the impact on research and innovation," Journal of Cleaner Production, vol. 281, 2021.

8. Y. N. Harari, Sapiens: A Brief History of Humankind, Harper, 2015.

9. ANEEL, Atlas of electricity from Brazil (Brasilia) (Original in Portuguese), 2016.

10. EPE, Brazilian Energy Balance 2016: Base year 2015, Empresa de Pesquisa Energética-Rio de Janeiro: EPE, 2016.

11. Niyom Suwandej, "Factors Influencing Total Quality Management," Procedia - Social and Behavioral Sciences, vol. 197, pp. 2215-2222, 2015.

12. M. Christopher, A. Payne, D. Ballantyne, Relationship Marketing: Creating Stakeholder Value, Butterworth-Heinemann, 2002.

13. A. Parasuraman, V. Zeithaml, L. L. Berry, "SERVQUAL: A multi-item scale for measuring consumer perceptions of the service quality," Journal of Retailing, vol. 64, no. 1, pp. 12, 1998.

14. R. L. Oliver, Satisfaction: A behavioral perspective on the consumer: A behavioral perspective on the consumer, New York: Routledge, 2014.

15. V. B. Veljković, O. S. Stamenković, Z. B. Todorović, M. L. Lazić, D. U. "Skala, Kinetics of sunflower oil methanolysis catalyzed by calcium oxide," Fuel, vol. 88, no 9, pp. 1554-1562, 2009.

16. S. Paliwoda, S, "Marketing's unseen macroeconomic contribution-consumer satisfaction: a research agenda," International Journal of Research in Marketing, 2013.

17. M. Luck, M. Benkenstein, "Consumers between supermarket shelves: The influence of interpersonal distance on consumer behavior," Journal of Retailing and Consumer Services, vol. 26, pp. 104-114, 2015.

18. C. Fornell, "A national customer satisfaction barometer: The Swedish experience," Journal of Marketing, vol. 56, no. 1, pp. 6-21, 1992.

19. C. Fornell, M. D. Johnson, E. W. Anderson, J. Cha, B. E. Bryant, "The American customer satisfaction index: nature, purpose, and findings," Journal of Marketing, vol. 60, no. 4, pp. 7-18, 1996.

20. E. W. Anderson, C. Fornell, "Foundations of the American customer satisfaction index," Total quality management, vol. 11, no. 7, pp. 869-882, 2000.

21. C. Gijón, T. Garín-Muñoz, T. Pérez-Amaral, R. López-Zorzano, "Satisfaction of individual mobile phone users in Spain," Telecommunications Policy, vol. 37, no. 10, pp. 940-954, 2013.

22. D. M. Martins, A. C. Faria, L. C. Prearo, A. G. S. Arruda, " The level of influence of trust, commitment, cooperation, and power in the interorganizational relationships of Brazilian credit cooperatives," RAUSP Management Journal, vol. 52, pp. 47-58, 2017.

23. P. Duarte, M. Raposo, H. Alves, " Using a Satisfaction Index to Compare Students' Satisfaction During and After Higher Education Service Consumption," Tertiary Education and Management, vol. 18, pp. 17-40, 2012.

24. J. F. Hair, W. C. Black, B. J. Babin, R. E. Anderson, R. L. Tatham, Multivariate Data Analysis, Pearson, 2005.

25. P. Hackl, A. Westlund, "On structural equation modelling for customer satisfaction measurement," Total Quality Management Business Excellence, vol. 11, no. 4, pp. 820-825, 2000 .

26. A. Osman, S. Ruswiati, R. S. Saputra, J. Saha, "Determinants of student satisfaction in the context of higher education: A complete structural equation modeling approach," British Journal of Marketing Studies, vol. 5, no. 6, pp. 1-14, 2017.

27. D. Gefen, D. Straub, M.-C. Boudreau, "Structural equation modeling and regression: Guidelines for research practice," Communications of the association for information systems, vol. 4, no. 1, pp. 7, 2000.

28. A. Jansson, G. B. Sundblad, S. Lundvall, J. Norberg, "Assessing Students' Perceived Learning and Contentment in Physical Education: A Scale Development Study and Structural Equation Modeling Analysis," Measurement in Physical Education and Exercise Science, vol. 23, no. 3 pp. 280-290, 2019.

29. R. D. Tobias, An introduction to partial least squares regression, In Proceedings of the twentieth annual SAS users group international conference, Orlando, vol. 20, SAS Institute Inc Cary, 1995.

30. B. Ahmadi-Nedushan, Multivariate statistical analysis of monitoring data for concrete dams, Doctor of Philosophy, McGill University, Montreal, 2002. 
31. O. M. Kvalheim, "Interpretation of partial least squares regression models by means of target projection and selectivity ratio plots," Journal of Chemometrics, vol. 24, pp. 496-504, 2010.

32. C. Nitzl, "The use of partial least squares structural equation modelling (PLS-SEM) in management accounting research: Directions for future theory development," Journal of Accounting Literature, vol. 37, pp. 19-35, 2016.

33. L. Lee, S. Petter, D. Fayard, S. Robinson, "On the use of partial least squares path modeling in accounting research," International Journal of Accounting Information Systems, vol. 12, no. 4, pp. 305-328, 2011.

34. X. Xiao, Structural equation modeling compared with ordinary least squares in simulations and life insurers' data, Dissertação, The University of Texas, Austin, 2013.

35. A. I. Nicolaou, K. L. Sedatole, N. K. Lankton, "Integrated information systems and alliance partner trust," Contemporary Accounting Research, vol. 28, no. 3, pp. 1018-1045, 2011.

36. M. Grigsby, Marketing Analytics: A Practical Guide to Improving Consumer Insights Using Data Techniques, Kogan Page, 2018.

37. Z. Huang, Clustering large data sets with mixed numericand categorical values, In: Proceedings of the First Pacific-Asia Conference on Knowledge Discovery and Data Mining, Singapore. Singapore: World Scientific, 1997.

38. H. F. Kaiser, "The varimax criterion for analytic rotation in factor analysis," Psychometrika, vol. 23, no. 3, pp. 187-200, 1958.

39. C. Fornell, D. F. Larcker, "Evaluating structural equation models with unobservable variables and measurement error," Journal of Marketing Research, vol. 18, no. 1, pp. 39-50, 1981.

40. J. Henseler, C. M. Ringle, R. R. Sinkovics, The use of partial least squares path modeling in international marketing, In New challenges to international marketing: Emerald Group Publishing Limited, 2009.

41. J. Nunnally, I. H. Bernstein. Psychometric theory, New York: McGraw-Hill Companies, 1994.

42. W. W. Chin, "The partial least squares approach to structural equation modeling," Modern methods for business research, vol. 295, no. 2, pp. 295-336, 1998.

43. M. Tenenhaus, V. E. Vinzi, Y.-M. Chatelin, C. Lauro, "PLS path modeling," Computational Statistics Data Analysis, vol. 48, no. 1, pp. 159-205, 2005.

44. D. Barclay, C. Higgings, R. "Thompson, The partial least squares (PLS) approach to casual modeling: Personal computer adoption and use as an illustration," Technology Studies, vol. 2, no. 2, pp. 285-309, 1995.

45. B. Efron, R. J. Tibshirani, An introduction to the bootstrap, CRC press, 1994.

46. M Keil, B. C. Tan, K. K. Wei, T.Saarinen, V. Tuunainen, A. Wassenaar, A. "A significance tests and goodness of fit in the analysis of covariance structures," MIS Quarterly, vol. 24, no. 2, pp. 299--325, 2000.

47. M. Tenenhaus, S. Amato, V. E. Vinzi, A global goodness-of-fit index for PLS structural equation modelling, In Proceedings of the XLII SIS scientific meeting, 2004.

48. J. F. Hair, M. L. Gabriel, V. K. Patel, "AMOS Covariance-Based Structural Equation Modeling (CB-SEM): Guidelines on its Application as a Marketing Research Tool," Revista Brasileira de Marketing, vol. 13, no. 2, pp. 44-55, 2014.

49. J. Henseler, M. Sarstedt, M. "Goodness-of-fit indices for partial least squares path modeling," Computational Statistics, vol. 28, no. 2, pp. 565-580, 2013.

50. L. Klem, "Reading and understanding more multivariate statistics," In: L. G. Grimm, P. R Yarnold, Structural equation modeling, Washington: American Psychological Association, 1995.

51. P. Mohajerani, "Customer satisfaction: A structural equation modeling analysis," Australian Journal of Business and Management Research, vol. 3, no. 3, pp. 1-10, 2013.

52. S. Chakraborty, K. Sengupta, "Structural equation modelling of determinants of customer satisfaction of mobile network providers: case of Kolkata, India," IIMB Management Review, vol. 26, no. 4, pp. 11-212, 2014.

53. M. S. Farooq, M. Salam, A. Fayolle, N. Jaafar, K. Ayupp, "Impact of service quality on customer satisfaction in Malaysia airlines: A PLS-SEM approach," Journal of Air Transport Management, vol. 67, pp. 169-180, 2018.

54. P. Duarte, S. C. Silva, M. B. Ferreira, "How convenient is it?: Delivering online shopping convenience to enhance customer satisfaction and encourage e-wom," Journal of Retailing and Consumer Services, vol. 44, pp. 161-169, 2018.

55. O'Neil Management Consulting LLC, Recommendations for Strengthening the Massachusetts Department of Public Utilitie's Service Qaulity Standards, Massachusetts, 2012. 
56. CEER, "5th Benchmarking report on quality of electricity supply," Energy Community, 2011.

57. IEEE - Institute of Electrical and Electronic Engineers," IEEE Guide for Electric Power Distribution Reliability Indices, 2001.

58. G. Rekettye, J. Pintér, "Customer satisfaction and price acceptance in the case of electricity supply," International Journal of Process Management and Benchmarking, vol. 1, no. 3, pp. $1-12,2006$.

59. E. Melo, E. M. A Neves, L. Pazzini, "Brazilian electricity sector restructuring: From privatization to the new governance structure," 2011 8th International Conference on the European Energy Market (EEM), pp. 905-910, 2011.

60. C. B. Astrachan, V. K. Patel, G. A. Wanzenried, "A comparative study of cbsem and PLSSEM for theory development in family firm research," Journal of Family Business Strategy, vol. 5, pp. 116-128, 2014.

61. A. Aljandali, Multivariate Methods and Forecasting with IBM SPSS Statistics, Springer, 2018.

62. W. Reinartz, M. Haenlein, J. Henseler, "An empirical comparison of the efficacy of covariancebased and variance-based SEM," Journal of Research in Marketing, vol. 26, pp. 332-344, 2009 .

63. R. H. Hoyle, Structural Equation Modeling: Concepts, Issues, and Applications, SAGE Publications, 1995.

64. D. Hooper, J. Coughlan, M. Mullen, "Structural equation modelling: guidelines for determining model fit," Electronic Journal of Business Research Methods, vol. 6, no. 1, pp. 53-60, 2008.

65. J. B. Schreiber, F. K. Stage, J. K. J., A. Nora, E. A. Barlow, "Reporting structural equation modeling and confirmatory factor analysis results: A review," The Journal of educational research, vol. 99, no. 6, pp. 323-338, 2006.

66. A. Adeniji, O. A. Osibanjo, J. A. Abiodun, E. Igbinoba, "Corporate Image: A Strategy for Enhancing Customer Loyalty and Profitability," Journal of South African Business Research vol. 2015, pp. 1-12, 2015.

67. P. M. Bentler, D. G. Bonett, "Significance tests and goodness of fit in the analysis of covariance structures," Psychological Bulletin, vol. 88, no. 3, pp. 588-606, 1980.

68. J. H. Steiger, A. Shapiro, M. W. Browne, "On the multivariate asymptotic distribution of sequential chi-square statistics," Psychometrika, vol. 50, no. 3, pp. 253-263, 1985.

69. S. S. Shapiro, M. B. Wilk, "An analysis of variance test for normality (complete samples)," Psychometrika, vol. 52, no. 3/4, pp. 591-611, 1965.

70. A. Satorra, P. M. Bentler, Corrections to test statistics and standard errors in covariance structure analysis, In: A. VON EYE AND C. C. CLOGG. Latent variables analysis. Thousand Oaks, CA, US: Sage Publications, 1994.

71. ANEEL, Quality in Distribution (Original in Portuguese), Brasília, Brasil, 2016.

72. ANEEL, Quality of Service (Original in Portuguese), Brasília, Brasil, 2016.

73. L. Dusky, "R Anatomy of a revolution," Executive Excellence, vol. 8, no. 5, pp. 19-20, 1991.

74. M. J. Sullivan, "Interruption costs, customer satisfaction and expectations for service reliability," IEEE Transactions on Power Systems, vol. 11, no. 2, pp. 989-995, 1996.

75. E. Fumagalli, P. Garrone, L. Grilli, "Service quality in the electricity industry: The role of privatization and managerial behavior," Energy Policy, vol. 35, no. 12, pp. 6212-6224, 2007.

76. W. O. Bearden, R. M. Durand, J. B. Mason, J. E. Tell, "Dimensions of consumer satisfaction/dissatisfaction with services: The case of electric utilities," Journal of the Academy of Marketing Science, vol. 6, no. 4, pp. 278--290, 1978.

77. O. A. Jannadi, S. Assaf, H. M. Maghraby, H. AL-Saggaf, "Service quality gaps analysis at SCECO-East, Saudi Arabia," a. Journal of Energy Engineering, vol. 126, no. 3, pp. 116-131, 2000 .

78. R. E. Brown, Electric Power Distribution Reliability, CRC Press, 2008.

79. IEC 61000-4-30:2003, Testing and measurement techniques - Power quality measurement methods, 2003.

80. EN 50160:1999, Voltage characteristics of electricity supplied by public distribution systems, 1999.

81. J. F. Hair, C. M. Ringle, M. Sarstedt, "PLS-SEM: Indeed a silver bullet," Journal of Marketing Theory and Practice, vol. 18, no. 2, pp. 139-152, 2011.

82. J. F. Hair, G. T. M. Hult, C. M. Ringle, M. Sarstedt, A primer on partial least squares structural equation modeling (PLS-SEM), Thousand Oaks: Sage, 2014. 
83. C. L. Shook, D. J. Ketchen, G. T. M. Hult, K. M. Kacmar, "An assessment of the use of structural equation modeling in strategic management research," Strategic Management Journal, vol. 25, no. 4, pp. 397-404, 2004.

84. C. Ringle, M. Sarstedt, J. F. Hair, T. Pieper, "The use of partial least squares structural equation modeling in strategic management research: A review of past practices and recommendations for future applications," Journal of Long Range Planning, vol. 45, no. 6, pp. 320-340, 2012

85. C. Fornell, F. L. Bookstein, "Two Structural Equation Models: LISREL and PLS Applied to Consumer Exit-Voice Theory," Journal of Marketing Research, vol. 19, no. 4, pp. 440-452, 1982.

86. H. Schneeweiß, "Models with Latent Variables: LISREL Versus PLS," Statistica Neerlandica, vol. 45, no. 2, pp. 145-157, 1991. 
